\title{
Chapter 2 \\ Flood Risk Management Practices in Morocco: Facts and Challenges
}

\author{
Dalila Loudyi, Moulay Driss Hasnaoui, and Ahmed Fekri
}

\begin{abstract}
From ancient flood management practices driven by agricultural activities to dam's policy for water resources management including flood protection, to the National Strategy for Natural Disaster Risk Integrated Management; Morocco has come a long way in flood risk management. This chapter describes the recurrent flooding phenomenon plaguing the country along with progress in flood risk assessment approaches in terms of technique, governance, and best practices. An extensive number of research articles, administrative documents, consultancy, and international organizations reports are analyzed to give a holistic up-to-date insight into flood risk management in Morocco and present a comprehensive and critical view from a scientific perspective. Information and data were collected from a range of various sources and synthesized to integrate all scientific and governance aspects. Though analysis of this landscape shows progresses made by the Government to protect the population and reduce flood risk, it also shows shortcomings and challenges still to be overcome. Thus, a SWOT analysis was carried out for scoping and identifying the strengths, weaknesses, opportunities, and threats pertaining to this issue. The analysis reveals various success and failure factors related to three major components: governance, risk assessment approaches, and flood risk mitigation measures sustainability.
\end{abstract}

Keywords Flood risk management - Morocco - SWOT • Flood risk assessment • Flood control measures

\footnotetext{
D. Loudyi $(\bowtie)$

Water, Environment and Climate Change Laboratory Team, Faculty of Science and Technology, Hassan II University of Casablanca, Mohammedia, Morocco e-mail: dalila.loudyi@fstm.ac.ma

M. D. Hasnaoui

Water Resources Division, Ministry of Equipment, Transport, Logistics and Water, Rabat, Morocco
}

A. Fekri

Applied Geology, Geomatics and Environment Laboratory, Faculty of Sciences Ben Msik, Hassan II University of Casablanca, Casablanca, Morocco

(C) The Author(s) 2022

T. Sumi et al. (eds.), Wadi Flash Floods, Natural Disaster Science and Mitigation

Engineering: DPRI Reports, https://doi.org/10.1007/978-981-16-2904-4_2 


\section{Acronyms}

\begin{tabular}{|c|c|}
\hline AAL & Average Annual Loss \\
\hline $\mathrm{ABH}$ & Hydraulic/River Basin Agency \\
\hline ACAPS & Insurance and Social Security Regulatory Authority \\
\hline AUA & Al Hoceima Urban Agency \\
\hline AUT & Taounate Urban Agency \\
\hline CAU & Urbanization Aptitude Map \\
\hline $\mathrm{CVC}$ & Coordination and Monitoring Center \\
\hline DEM & Digital Elevation Model \\
\hline DGE & General Directorate of Water \\
\hline DGM & General Directorate of Meteorology \\
\hline DGPC & Civil Protection Directorate \\
\hline DGRN & Natural Disasters Risk Management Directorate \\
\hline DRPE & Water Research and Planning Directorate \\
\hline EMDAT & $\begin{array}{l}\text { The OFDA/CRED International Disaster Database, www.emdat.be- } \\
\text { Université catholique de Louvain-Brussels, Belgium }\end{array}$ \\
\hline FFWS & Flood Forecasting and Warning System \\
\hline FLCN & Fund to combat Effects of Natural Disasters \\
\hline FSEC & Fund of Solidarity against Catastrophic Events \\
\hline GIS & Geographical Information System \\
\hline HCEFLCD & $\begin{array}{l}\text { High Commissioner for Water, Forests and the Fight against } \\
\text { Desertification }\end{array}$ \\
\hline IDF & Intensity-Duration-Frequency \\
\hline IPCC & Intergovernmental Panel on Climate Change \\
\hline JICA & Japan International Cooperation Agency \\
\hline LEC & Loss Exceedance Curve \\
\hline LTE & Long-Term Evolution \\
\hline LYDEC & Lyonnaise des Eaux of Casablanca, water utility \\
\hline MAD & Moroccan Dirham (10 MAD is about 1 USD) \\
\hline MI & Ministry of Interior \\
\hline MnhPRA & Morocco natural hazards Probabilistic Risk Analysis \\
\hline OECD & Organisation for Economic: Co-operation and Development \\
\hline ONE & National Office for Energy \\
\hline ONEE & $\begin{array}{l}\text { National Office for Energy and Drinking Water (merger of former } \\
\text { ONE and ONEP) }\end{array}$ \\
\hline ONEP & National Office for Drinking Water \\
\hline ORMVA & Regional Agricultural Development Office \\
\hline ORSEC & Local Emergency Response Plan \\
\hline $\mathrm{PCC} / \mathrm{RCC}$ & Provincial/Regional Coordination Center \\
\hline PDAIRE & Master Plan for Integrated Water Resources Management \\
\hline PNE & National Water Plan \\
\hline PNI & National Flood protection Plan \\
\hline PPRI & Prevention Plan against Flood Risk \\
\hline $\mathrm{RCM}$ & Regional Climate Models \\
\hline
\end{tabular}




$\begin{array}{ll}\text { SCO } & \text { Western mega-drainage channel of Casablanca city } \\ \text { SDACR } & \text { Master Plan for Risk Analysis and Coverage } \\ \text { SNE } & \text { National Water Strategy } \\ \text { UAV } & \text { Unmanned Aerial Vehicle } \\ \text { UNDP } & \text { United Nations Development Programme } \\ \text { UNDRO } & \text { United Nations Disaster Relief Coordinator-UNDRO } \\ \text { UNDRR } & \text { United Nations Office for Disaster Risk Reduction } \\ \text { UNEP } & \text { United Nations Environment Programme } \\ \text { UNESCO } & \text { United Nations Educational, Scientific and Cultural Organization } \\ \text { UNISDR } & \text { United Nations International Strategy for Disaster Reduction } \\ \text { WB } & \text { World Bank }\end{array}$

\subsection{Introduction}

As a country with an agriculture-based economy under arid to semi-arid climate conditions, Morocco has traditionally developed its agriculture on its vast and plentiful floodplains due to their water availability and favorable topography for many types of crops. Consequently, many Moroccan farmers have built up flood management practices based on floodwater control for irrigation. For example, the use of dikes designed to erode in a controlled manner during a flood event and spread floodwaters was part of ancestral irrigation knowledge. In fact, floods have always been regarded as a relief from water scarcity for agriculture and a gift of nature that ensures prosperity and the well-being of local populations. However, there has been a paradigm shift driven by an increase in urbanization and the fading of traditional agriculture that have turned floods into an impediment to modern societal development. Gradually, protecting cities and farmlands in the vicinity of watercourses from floods in addition to mitigating recurrent droughts has become a governmental priority. As a consequence, at an early stages of the country independence, Morocco developed a dam's policy which began in 1967 (Jouve 2006). The policy aimed at the design and construction of two to three dams each year in order to irrigate one million hectares by the year 2000, secure drinking water supply, mitigate flood risk and produce hydropower. This dam's policy, designed initially for drought control and agricultural development, led to important investments in the water sector that rapidly proved to be beyond the state budget capacities. It raised the question of water cost, tariffication issues of water services (i.e. drinking water, irrigation, and energy), and the respective cost sharing between the state and users. As an institutional response to this problem, a hydrological landscape-based division was introduced in 1995 by the water law 10-95, creating nine catchment agencies, called Hydraulic Basin Agencies $(\mathrm{ABH})$ that provide administrative, financial, and technical framework for integrated water resources assessment and management at regional levels. Hence, in 1999, the first ABH of Oum Er Rbia (ABHOER) was created, followed by Sebou (ABHS), Tensift 
(ABHT), Bouregreg-Chaouia (ABHBC), Moulouya (ABHM), and Souss-Massa-Draa (ABHSMD) in 2000; Loukkos (ABHL) in 2001; Guir-Ziz-Rheris (ABHGZR) and Sakia el Hamra-Oued Eddahab (ABHSO) in 2009. In 2016, a tenth $\mathrm{ABH}$ was created by dividing the Souss-Massa-Draa catchment into two separate administrative entities that are known as Souss-Massa ABH (ABHSM) and Draa Oued Noun ABH (ABHDON). This was due to the extent of this territory and its numerous water challenges which include both droughts and floods (Fig. 2.1). This set of ABHs serves as the regional administrative framework for water management planning including flood risk management. Moreover, between 1951 and 2019, Morocco experienced more than 80 flood events showing that despite the success of many dams in ensuring flood protection, many of them are still unable to prevent downstream flooding (e.g. Wahda 2008; Guelmim 2014; El Malleh 2002). Besides revealing the persistent lack of structural and non-structural measures in many Moroccan zones, the recurrent flooding raised the question of new risk management approaches. This chapter describes the phenomenon of floods in Morocco, the existing approaches to assess flood risk, their related technical and governance aspects, and the adopted best management practices. An analysis of the existing approaches will be carried out and recommendations for improving it will be provided.

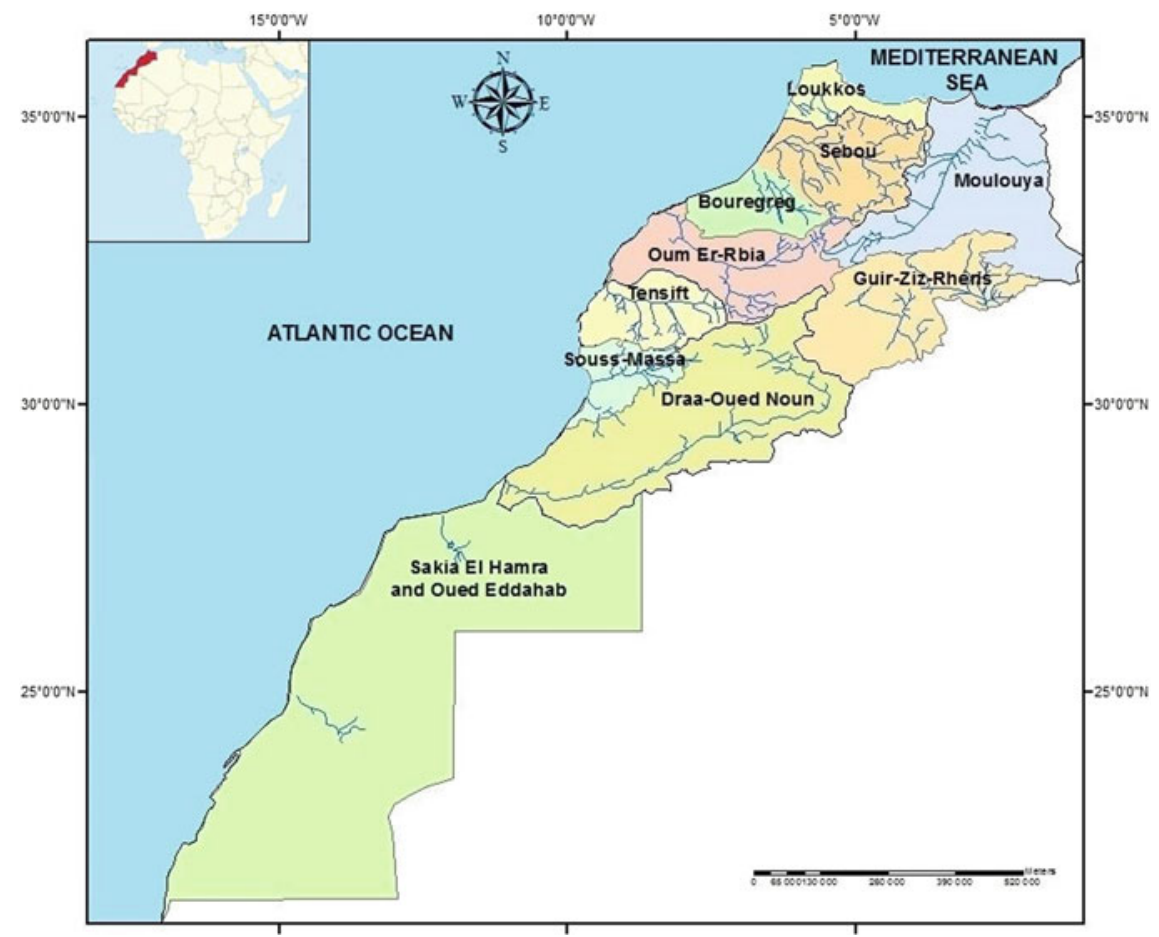

Fig. 2.1 The ten Hydraulic Basin Agencies (ABHs) boundaries for regional integrated water management and planning in Morocco 


\subsection{Overview of Flood Events in Morocco}

\subsubsection{Flood Events Historical Data}

In the past twenty years, Morocco was hit by multiple natural disasters such as $\mathrm{Al}$ Hoceima earthquake (February, 2004), Taourart-Akchour landslide in the Rif mountains (November, 2010) and floods that affected large cities such as Mohammedia (November 2002), Tangier (October 2008, December 2009, January 2013), Casablanca (November 2010 and January 2013), plains such as Gharb (2008) and, lately, desertic areas of Guelmim and Sidi Ifni in southern Morocco (November, 2014), Laayoune-Saquia Al Hamra (October, 2016) and Taroudant (2019). Disasters history shows that, since 1970, floods are events that impacted the most people in Morocco and caused important economic damages (Fig. 2.2). An inventory of past flood events over Moroccan territory with their damages for the last fifty years is shown in Table 2.1.

Many international database resources can be found for recording flood events in Morocco. A research dedicated resource is the EM-DAT database of the University of Louvain for all disasters (EM-DAT 2020). On an administrative level, the Moroccan department of environment used to update regularly the United Nation Disaster Risk Reduction (UNDRR) system DesInventar Sendai database with information on floods, landslides, forest fires, droughts, and earthquakes (DesInventar Sendai 2014). Currently, natural disaster management is the responsibility of the Ministry of Interior leading to a new approach of data communication on disasters.

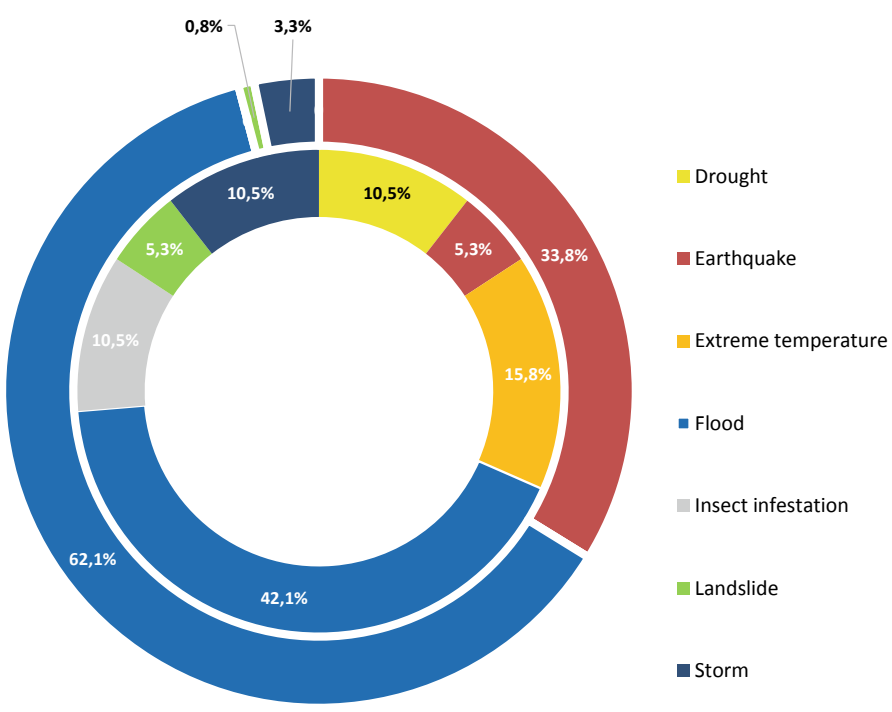

Fig. 2.2 Reported natural disaster events in Morocco 1970-2020: frequency (internal ring); number of deaths (external ring) (Source EM-DAT) 
Table 2.1 Inventory of past flood events over Moroccan territory and related damages 1970 2020

\begin{tabular}{|c|c|c|c|c|c|}
\hline Year & Date & Location & Flood causes & Deaths & Economic damages \\
\hline 1970 & $\begin{array}{l}22 \\
\text { January }\end{array}$ & Northern region & & 11 & USD 30 million \\
\hline 1975 & 21 April & Western provinces & & 10 & \\
\hline 1979 & $\begin{array}{l}25 \\
\text { October }\end{array}$ & Ouarzazate & & 16 & \\
\hline 1985 & $\begin{array}{l}07 \\
\text { January }\end{array}$ & Guelmim & $\begin{array}{l}33-65 \mathrm{~mm} / \\
53 \mathrm{~min}, \\
\text { Oum } \\
\text { Laachar } \\
\text { wadi }\end{array}$ & & \\
\hline 1995 & 01 April & Tata & Akka wadi & 18 & $\begin{array}{l}2 \text { wounded, } 4 \text { missing, } \\
\text { and } 350 \text { families } \\
\text { homeless; as well as } \\
\text { destruction of } 655 \\
\text { homes, about USD } 9 \\
\text { million }\end{array}$ \\
\hline 1995 & $\begin{array}{l}17-19 \\
\text { August }\end{array}$ & Ourika valley & Ourika wadi & 730 & USD 9 million \\
\hline 1995 & $\begin{array}{l}04 \\
\text { September }\end{array}$ & Taza-Taounate & Amlil wadi & 43 & \\
\hline 1996 & $\begin{array}{l}21 \text { Jan. to } \\
01 \text { Feb. }\end{array}$ & Beni Mellal & & 25 & USD 55 million \\
\hline 1997 & $\begin{array}{l}28-29 \\
\text { September }\end{array}$ & El Hajeb & & 60 & \\
\hline 2000 & $\begin{array}{l}22 \\
\text { December }\end{array}$ & Martil plain-Tetouan & & 6 & \\
\hline 2001 & $\begin{array}{l}23-26 \\
\text { December }\end{array}$ & Settat-Essaouira & & 15 & USD 2.2 million \\
\hline 2002 & $\begin{array}{l}24-29 \\
\text { November }\end{array}$ & $\begin{array}{l}\text { Mohammedia, } \\
\text { Berrechid, Settat, Fez }\end{array}$ & & 80 & $\begin{array}{l}17 \text { wounded, } 26 \\
\text { missing, } 44 \text { industrial } \\
\text { units, fire at la SAMIR } \\
\text { oil refinery, } 1334 \\
\text { homes damaged, many } \\
\text { hectares of agricultural } \\
\text { land and livestock lost; } \\
\text { USD } 200 \text { million }\end{array}$ \\
\hline 2003 & $\begin{array}{l}17-18 \\
\text { November }\end{array}$ & Nador_El Hoceima & & 35 & \\
\hline 2006 & $\begin{array}{l}26-28 \\
\text { May }\end{array}$ & Errachidia & & 6 & \\
\hline 2006 & 26 May & Merzouga & $\begin{array}{l}112 \mathrm{~mm} / \\
3 \mathrm{~h}, \mathrm{El} \\
\text { Beida and } \\
\text { Tisserdmine } \\
\text { wadis }\end{array}$ & & $\begin{array}{l}140 \text { houses and hotels, } \\
\text { deterioration of Taouz- } \\
\text { Merzouga road and } \\
\text { ONEP (National Office } \\
\text { for Drinking Water) } \\
\text { water supply pipes of } \\
\text { Merzouga and Taouz } \\
\text { villages }\end{array}$ \\
\hline
\end{tabular}


Table 2.1 (continued)

\begin{tabular}{|c|c|c|c|c|c|}
\hline Year & Date & Location & Flood causes & Deaths & Economic damages \\
\hline 2006 & $\begin{array}{l}25-27 \\
\text { October }\end{array}$ & Essaouira-Safi & & 11 & \\
\hline 2008 & $\begin{array}{l}26-28 \\
\text { February }\end{array}$ & Marrakech & & 9 & \\
\hline 2008 & $\begin{array}{l}23 \text { Oct. to } \\
03 \text { Nov. }\end{array}$ & Tanger & & 30 & $\begin{array}{l}\text { Industrial units } \\
\text { important damages }\end{array}$ \\
\hline 2009 & $\begin{array}{l}1-12 \\
\text { February }\end{array}$ & $\mathrm{Al}$ Gharb region & & 29 & $\begin{array}{l}400 \text { homes and } \\
100,000 \text { ha of land } \\
\text { destroyed }\end{array}$ \\
\hline 2009 & $\begin{array}{l}25-26 \\
\text { December }\end{array}$ & Middle Draa Valley & & 5 & \\
\hline 2010 & $\begin{array}{l}27 \\
\text { November }\end{array}$ & Bouskoura & $\begin{array}{l}195 \mathrm{~mm} / \\
24 \mathrm{~h}\end{array}$ & & $\begin{array}{l}\text { Schools, national } \\
\text { phosphate production } \\
\text { company } \\
\text { (OCP) headquarter, } \\
\text { several buildings, and } \\
\text { Roads are flooded } \\
\end{array}$ \\
\hline 2010 & 09 March & $\begin{array}{l}\text { El Ksiba, Taza, } \\
\text { Midelt, Khénifra }\end{array}$ & $\begin{array}{l}200 \mathrm{~mm} / \\
24 \mathrm{~h} \text { with a } \\
\max \text { of } \\
25 \mathrm{~mm} / 1 \mathrm{~h}\end{array}$ & 10 & \\
\hline 2010 & $\begin{array}{l}25 \text { Oct. to } \\
06 \text { Nov. }\end{array}$ & $\begin{array}{l}\text { Tiflet, Al Hoceima, } \\
\text { Khenifra area, } \\
\text { Ouezzane, Bouznika, } \\
\text { Ouarzazate, Zagora, } \\
\text { Salé, Rabat, } \\
\text { Casablanca }\end{array}$ & & 32 & USD 29 million \\
\hline 2012 & $\begin{array}{l}31 \\
\text { October }\end{array}$ & Taroudant, Agadir & $\begin{array}{l}84-100 \mathrm{~mm} / \\
12 \mathrm{~h}\end{array}$ & & \\
\hline 2013 & 29 August & Tetouan, M'diq & $31 \mathrm{~mm} / 3 \mathrm{~h}$ & & \\
\hline 2014 & $\begin{array}{l}28-30 \\
\text { November }\end{array}$ & $\begin{array}{l}\text { Guelmim region/Sidi } \\
\text { IfnI }\end{array}$ & $\begin{array}{l}\text { Bousafen } \\
\text { and Oum el } \\
\text { Achar wadis }\end{array}$ & 60 & $\begin{array}{l}\text { More than } 32 \text { fatalities } \\
\text { and damages due to } \\
\text { inundations }\end{array}$ \\
\hline 2016 & 4-5 May & Taroudant-Ouarzazate & Azkrou wadi & 4 & \\
\hline 2017 & $\begin{array}{l}23 \\
\text { February }\end{array}$ & Sale-Rabat & $\begin{array}{l}120 \mathrm{~mm} / \\
24 \mathrm{~h} \text { with a } \\
\max 65 \mathrm{~mm} / \\
1 \mathrm{~h}\end{array}$ & & $\begin{array}{l}\text { National Road n6- } \\
\text { Lâarjate road partly } \\
\text { destroyed }\end{array}$ \\
\hline 2018 & 17 August & Zagora & & & \\
\hline 2018 & $\begin{array}{l}25-26 \\
\text { September }\end{array}$ & Tata & & & \\
\hline 2019 & 28 August & Taroudant region & & 8 & 200 homes destroyed \\
\hline 2019 & $\begin{array}{l}08-09 \\
\text { September }\end{array}$ & Errachidia & $\begin{array}{l}\text { Damachine } \\
\text { wadi }\end{array}$ & 17 & 27 wounded \\
\hline
\end{tabular}




\subsubsection{Flood Types Description}

An analysis of historical flood events in Morocco shows that the nature of these floods can be classified as follows:

- Wadi floods of large catchments, with an area generally greater than $10,000 \mathrm{~km}^{2}$, where watercourses gradually take over their banks. Such is the case of Moulouya, Sebou, Oum Er Rbia, Tensift, Souss, Drâa, and Ziz wadis.

- Flash floods of the main tributaries of large wadis, with a rise time between 6 and $24 \mathrm{~h}$. It is the case of Moulouya tributaries (e.g. Melloulou, Za), Sebou tributaries (e.g. Ouergha, Beht), Oum Er Rbia tributaries (e.g. El Abid, Tessaout, Lakhdar), Tensift tributaries (e.g. N'Fis), Souss tributaries (e.g. Issen), Drâa tributaries (e.g. Dadès, Ouarazazte, N'Ait Douchéne) and Ziz tributaries (e.g. Rhéris, Todgha).

- Flash floods of the coastal Mediterranean wadis (e.g. Nekor, El Had, Lao, Emsa, Martil) and coastal Atlantic wadis (Mharhar, El Hachef, Loukkos, Bouregreg, Ykem, Cherrat, El Mellah, Nfifikh, Tamdrost, Ksob, Tamri, Massa). Their related watersheds surfaces range generally between $300 \mathrm{~km}^{2}$ and $3000 \mathrm{~km}^{2}$, with a rise time of one to few hours.

- Semi-flash floods of medium-sized plains with flat water flow, on the plains located at the foothills of Rif and the Atlas Mountains. Slopes abruptly diminish and the conveyance capacity of wadis from high mountains to their foothills then decreases sharply (e.g. Tamdrost, Mazer, Issyl).

- Torrential flash floods of small mountain basins in Rif and Atlas, characterized by steep slopes, generally with rugged, unvegetated, and impervious lands, where the heaviest daily maximum rains are recorded (e.g. Ourika, Rhéraya, Toghdra, Nfis, Fnideq, Charâa valleys). The rise time of these type of floods is less than one hour and often applies to urban areas that are large (e.g. Marrakech, Mohammedia, Settat, Berrechid, Béni Mellal, Errachidia, Oujda) and located in the vicinity of wadis.

- Urban stormwater floods, generated by rainfall on impervious parts of the city or runoff of small upstream basins (e.g. Tangier, Casablanca, Fez, Azrou, El Hajeb).

Based on the sixty years record of flood events in Morocco, the National Water Plan of Morocco (PNE 2015) reported that the main reasons can be broadly summarized in the following points:

- rapid and uncontrolled development of urbanization in flood-prone areas,

- lack of integrating flood risk in urban planning documents,

- lack of maintenance of watercourses,

- insufficient sections of hydraulic structures to convey floodwater (e.g. channels, culverts, nozzles). They generally suffer from an undersizing which is sharply exacerbated in urban areas,

- localized solutions to flood-prone areas without any integrated approach: most structural measures in urban areas are carried out without considering neither 
works located immediately upstream nor for possible downstream impacts. The problem aggravates even more with development work on a long stretch of a watercourse (e.g. recalibration, containment, undergrounding),

- deficiencies in maintenance of underground hydraulic structures (e.g. culverts, nozzles, pipes) that are often the default solutions for flood control in urban area based on their sewage networks,

- poor knowledge of the flood dynamic (meteorological conditions, role of the oceans, fine spatial and temporal distribution of precipitation, rainfall-runoff relationship, watershed morphology role, landcover, and the land use, flood probability, climatic drivers, etc.). This is particularly true at local levels,

- climate change and increase of intensity of extreme rainfall episodes. Indeed, despite its arid and semi-arid climate, Morocco has experienced in the past 30 years an increase in the frequency of flood events.

\subsubsection{Climate Change and Extreme Rainfall Trends}

Due to its geographical location and geomorphological features, Morocco's climate is Mediterranean in the north and arid in the south and southeast. Average annual temperature is $17.5^{\circ} \mathrm{C}$, and average annual precipitation is $318.8 \mathrm{~mm}$ with yet a great interannual, seasonal and spatial variability (Fig. 2.3). Precipitation patterns vary interannually from $50 \mathrm{~mm}$ to $100 \mathrm{~mm}$ in dry years and $300 \mathrm{~m}$ to $400 \mathrm{~m}$ in wet years (Driouech 2010). Alternation of wet and dry episodes that can last several years is a defining feature of climatic and hydrological regimes of Morocco. Figure 2.4 shows the monthly distribution of temperature and precipitation for the period 1901-2016 (WB 2016). Morocco's rainy season extends from October through April, often resulting in devastating floods. High-intensity precipitations occur mainly in November to February, but can also occur in summer as a thunderstorm on the Atlas and Rif mountains.

According to the Intergovernmental Panel on Climate Change (IPCC), average annual precipitation will decrease in most of the Mediterranean region between $-4 \%$ and $-27 \%$. Number of rainy days is also expected to decrease with an increased risk of drought (IPCC 2007).

Climate change scenarios with $50 \mathrm{~km}$ resolution on Moroccan territory were performed by Driouech 2010 using ARPEGE-RV model. They showed that there will be a high spatial variability in magnitude evolution of extreme winter rainfall. The north-west and east of the country as well as part of the middle and high Atlas would not undergo significant changes. Yet, south of Morocco would experience less intense precipitation and the central coastal area would witness a relative increase in amplitude of heavy precipitation events. The number of extreme rainfall events, on the other hand, would decrease throughout the territory (Fig. 2.5a).

With higher resolution of $12 \mathrm{~km}$, two simulations for two of 30 years each (1971-2000 and 2021-2050) were carried out with ALADINClimat to assess future 


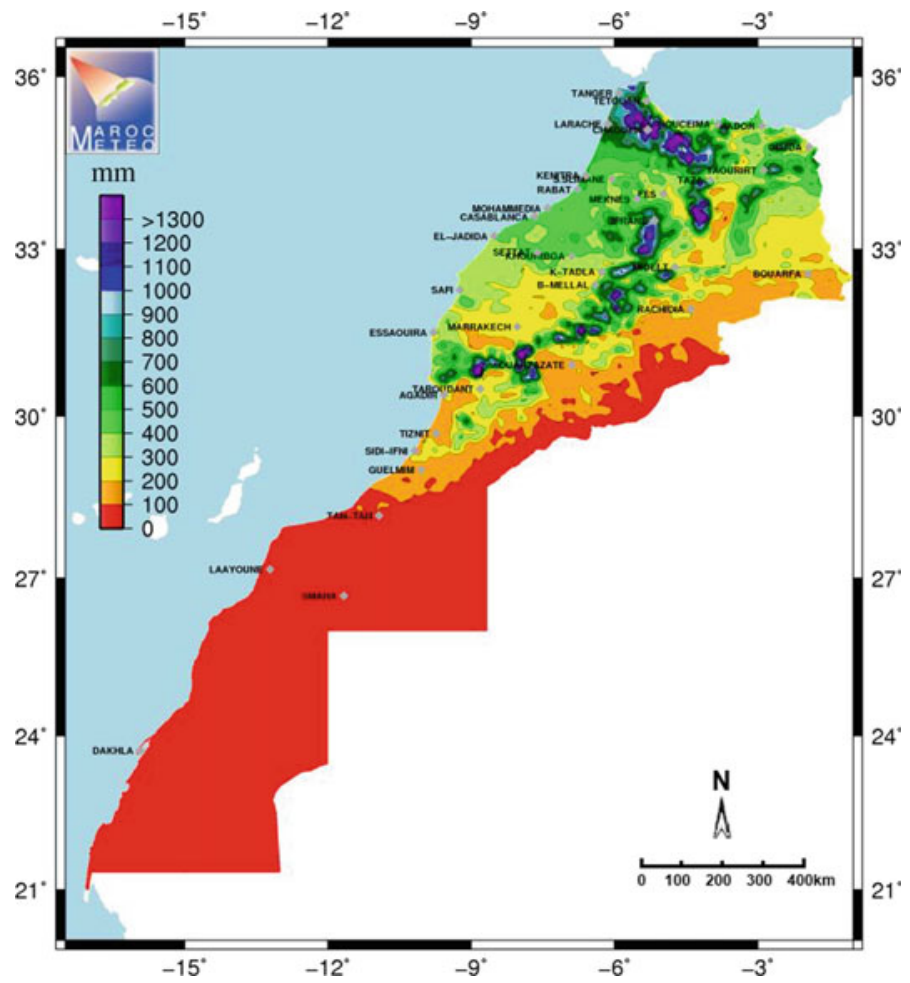

Fig. 2.3 Annual mean precipitations in Morocco for the period 1981-2010 (Source DGM 2017)

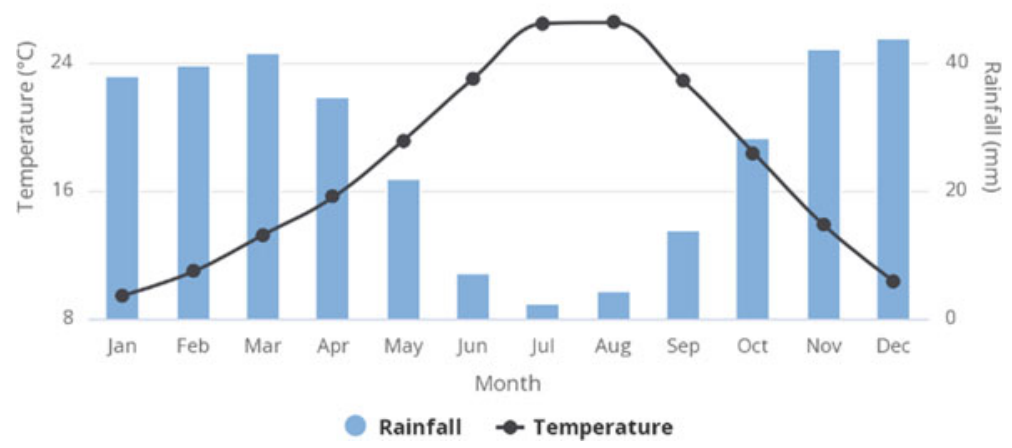

Fig. 2.4 Average monthly temperature and rainfall in Morocco for the period 1901-2016 (Source WB 2016) 
a)

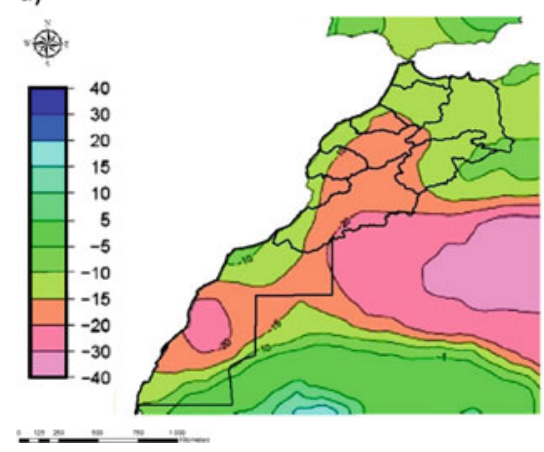

b)

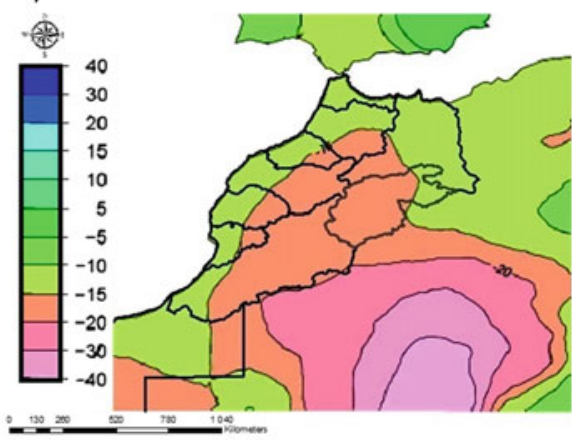

Fig. 2.5 Variation (in \%) of extreme rainfall events numbers for A1B scenario winter season, for 2021-2050 based on 1971-2000 record simulated change a by ARPEGE-RV-50 km resolution, b by ALADINClimat-12 km resolution (Modified from Driouech 2010)

changes in the northern half of Morocco. The results showed that winter precipitation would decrease by $-10 \%$ to $-15 \%$ over most of the northern part of the country where there will also be an increase in the maximum period of drought and a decrease in the number of wet days. Extreme rainfall events would not undergo significant amplitude evolutions on all the zone west of the Atlas Mountains and the extreme north. Yet, they will decrease in number from $-10 \%$ to $-20 \%$ on the whole northern part of Morocco covered by the domain of the model (Fig. 2.5b). Average spring precipitation is expected to increase by $+5 \%$ to $+20 \%$ over the northern half of the country with the exception of the northwest coastal region between Tangier and Casablanca, which is not expected to change significantly. The drying up of the north of the country in summer is also forecast by large majority of regional climate models (RCMs). In autumn, practically the entire area west of the Atlas Mountains would not change in terms of average precipitation.

Sinan and Belhouji (2016) estimated an overall decrease in annual precipitation totals varying on average between $10 \%$ and $30 \%$ depending on the scenario chosen and regions for horizon 2080-2100. Average annual temperatures will concomitantly increase on average between +2 and $+5{ }^{\circ} \mathrm{C}$ depending on the chosen scenario and the region considered. The impact of these variations on water resources volume is expected to have an overall downward trend ranging from $-7.6 \%$ to $-40.6 \%$.

\subsubsection{Hydrological Impact of Climate Change}

Rainfall-runoff process is tightly influenced by watersheds geomorphological and hydrological characteristics. Moroccan landscape can broadly be divided into two categories: mountains and plains. Most of Moroccan wadis cross plains that are 


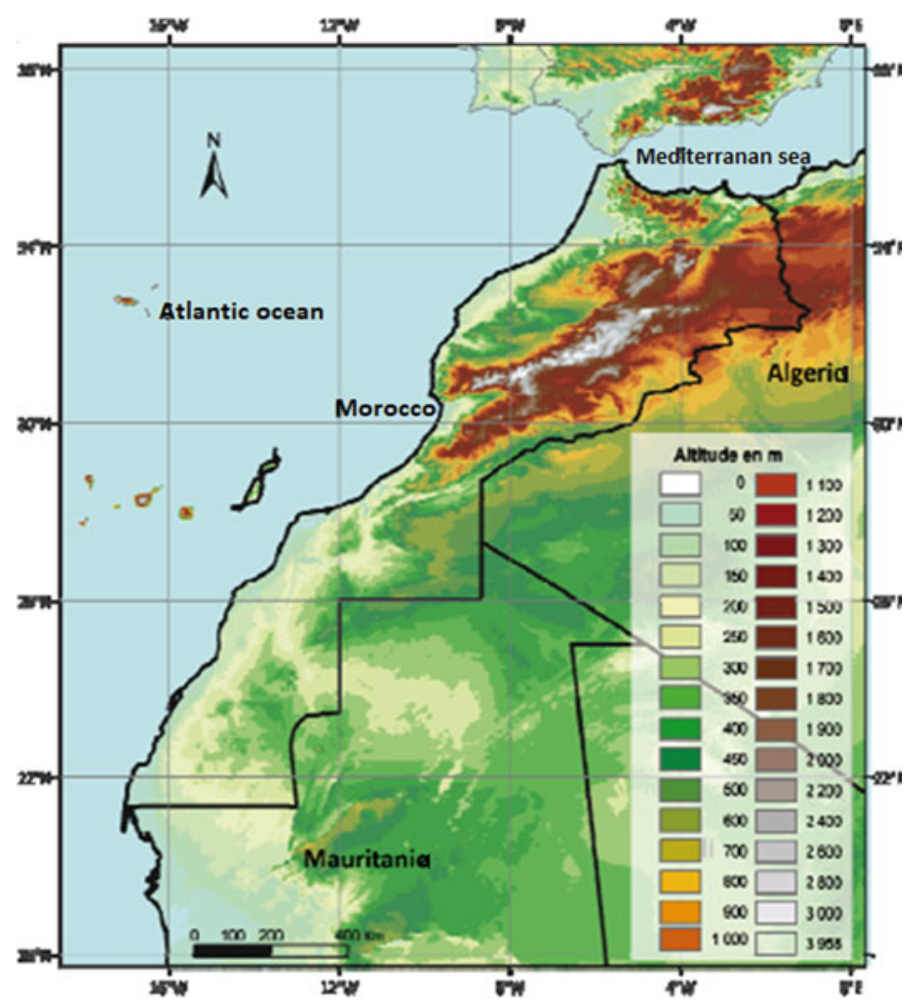

Fig. 2.6 Digital elevation model (DEM) map of Morocco (Source Singla 2009)

generally alluvial. Coastal and inland plains are large between the Atlantic Ocean and the Atlas Mountains, and get narrower on northern coastlines between the Mediterranean Sea and the Rif mountains (Fig. 2.6). In the South, plains and desert hills lay from the Anti-Atlas Mountains to the Moroccan southern Sahara. Rif Mountains in the North of the country, culminate at $2456 \mathrm{~m}$. As for the Atlas chain (i.e. Middle Atlas, High Atlas and Anti-Atlas), it extends from the North-East to the South-West and its highest point is $4165 \mathrm{~m}$. The mountains thus play the role of climatic barriers, regulating the rainfall over the northern part of the country.

At catchment level, few studies have tackled the impact of climate change on rainfall-runoff relationship in Morocco. Driouech et al. (2010) assessed the impact of climate change on Moulouya catchment of $55,500 \mathrm{~km}^{2}$ surface north east Morocco. The GR2M hydrologic model was run using ARPEGE-Climat model output scenarios with 50-60 km resolution. Between 1958 and 2000, monthly flows showed a clear downward trend mainly attributed to a decrease in rainfall and an increase in evapotranspiration (ET). By 2050, winter flow discharges are projected to decrease by -20 to $-30 \%$, those of other seasons would decrease less (on average +7 to $+10 \%)$. 
In Diekkrüger et al. (2012), climate scenarios showed that Drâa catchment, a $28,400 \mathrm{~km}^{2}$ basin in south eastern Morocco, will face a decrease in rainfall of $30 \pm 11 \mathrm{~mm}$ and an increase in temperature up to $1.4 \pm 0.7^{\circ} \mathrm{C}$ up to 2050 . Rainfall variability and evapotranspiration will increase which results in a reduced vegetation coverage amplifying rainfall effects. Consequently, an increase in the erosion rate up to $21 \pm 17 \%$ is expected.

On the Oum Er Rbia catchment, a basin with a total area of $36,972 \mathrm{~km}^{2}$, Azhari and Loudyi (2019) built up statistical downscaling scenarios to predict future climate. The models showed an increase in temperature fluctuating between $0.8 \%$ and $15.4 \%$, and a decrease in precipitation that varies from $3 \%$ to $16.4 \%$. The impact of these variations was simulated using the hydrologic model HEC-HMS resulting in a decrease of runoff discharge ranging from $48.4 \%$ to $57.1 \%$ over the basin area.

On a smaller scale, Marchane et al. (2017) carried out five regional climate models to evaluate future changes in precipitation and temperature over Rheraya watershed, a sub-basin at the Tensift catchment of $225 \mathrm{~km}^{2}$ surface located in the High Atlas Mountains of Morocco. The models were developed through the Med-CORDEX initiative, according to the two emissions scenarios RCP4.5 and RCP8.5. The future projections for the period 2049-2065 under the two scenarios indicate higher temperatures $\left(+1.4{ }^{\circ} \mathrm{C}\right.$ to $\left.+2.6{ }^{\circ} \mathrm{C}\right)$ and a decrease in total precipitation $(-22 \%$ to $-31 \%)$. The hydrological projections under these climate scenarios indicate a significant decrease in surface runoff $(-19 \%$ to $-63 \%$, depending on the scenario and hydrological model) mainly caused by a significant decline in snow amounts and increased temperature.

Seif-Ennasr et al. (2016) found that, under RCP8.5 scenario, temperatures in the Chtouka Ait-Baha sub-basin in the Souss Massa catchment, will increase up to $2{ }^{\circ} \mathrm{C}$ during 2030-49 and up to $5{ }^{\circ} \mathrm{C}$ during 2090-2100 compared to baseline (19862005). Precipitation will also decrease down to $-30 \%$ for the period 2030-2049 as well as to $-60 \%$ for 2080-2099 period. Subsequently, hydraulic simulations showed that water deficit at the basin will triple by year 2050 due to the reduction of aquifer recharge and dam's storage.

Many ABHs are still carrying out studies on the impact of climate change on their water resources within the process of updating their Master Plan for Integrated Water Resources Management, (e.g. Sebou, Souss Massa). Mitigation and adaptation measures are being identified as a result of these studies so that they can be included in the investment program drawn by the Master Plan of each of the ten Moroccan ABHs.

Research and technical studies show that there is a general trend to a decreasing total annual rainfall and an increase in temperature for next fifty years at national and local levels. However, no study has made a downscaling to simulate the trend in the intensity of extreme rainfall events, especially for short durations of few hours, that are often the cause of flash floods. Runoff is also expected to decrease as a natural consequence of decreasing rainfall in most catchments of the country. An exception can be the northern catchments of Loukkos and Sebou given the possible increase in precipitation pattern, the size, and shape of their watersheds having rapid hydrological responses especially those in Rif mountainous areas. 


\subsection{Flood Risk Management Framework}

\subsubsection{Management Approach}

As an arid and semi-arid country, the unexpected occurrence of flash floods was first handled in a crisis management manner. The frequency of events and their generated damages urged the government to prepare a strategy for flood management moving from crisis management to risk management (Fig. 2.7). Indeed, in a study published by OECD 2017 on risk management policies in Morocco, it was clear that a reactive approach did not enable an upstream preparation and identification of management, financial, and logistics needs for emergency situations, and therefore, pushed decision-makers to seek a proactive management approach.

\subsubsection{Institutional, Legal, and Policy Frameworks}

Morocco's institutional and legislative frameworks for flood risk management are broad and progressive. As the management approach was evolving from crisis management to proactive management, many institutions have seen their role changing by necessary legislative and regulatory updates. The nature of flood risk as an inter-sectorial field, correlating natural disaster, water management, environment, and public safety, has produced a wide array of actors involved in its planning and management as shown in Fig. 2.8. Introduction of the main flood management stakeholders is given below.

\section{(a) National and regional institutions}

The General Directorate of Water (DGE): Water resources planning is mainly the responsibility of the Water Department in Morocco. Within this department, the Directorate of Water Research and Planning (DRPE) is in charge of integrated

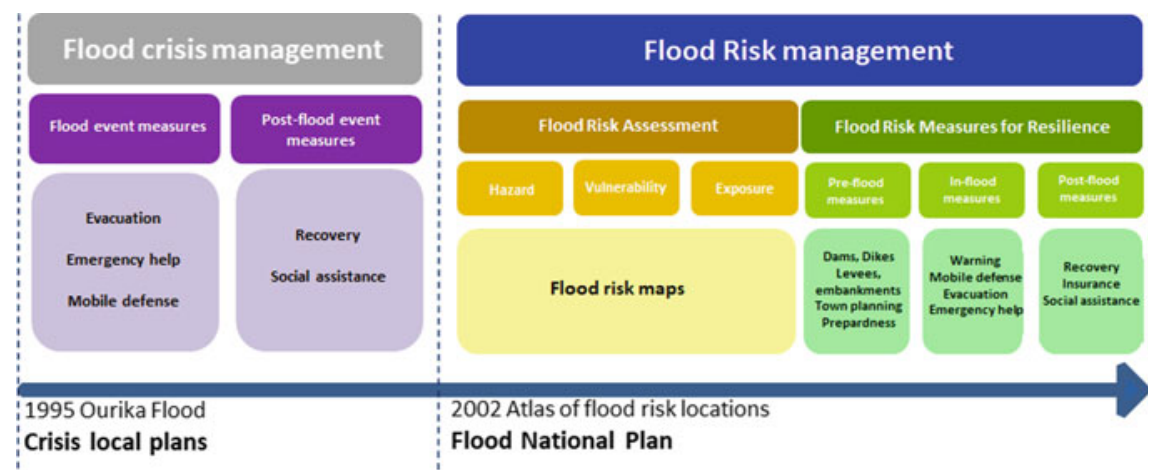

Fig. 2.7 Flood risk management framework 


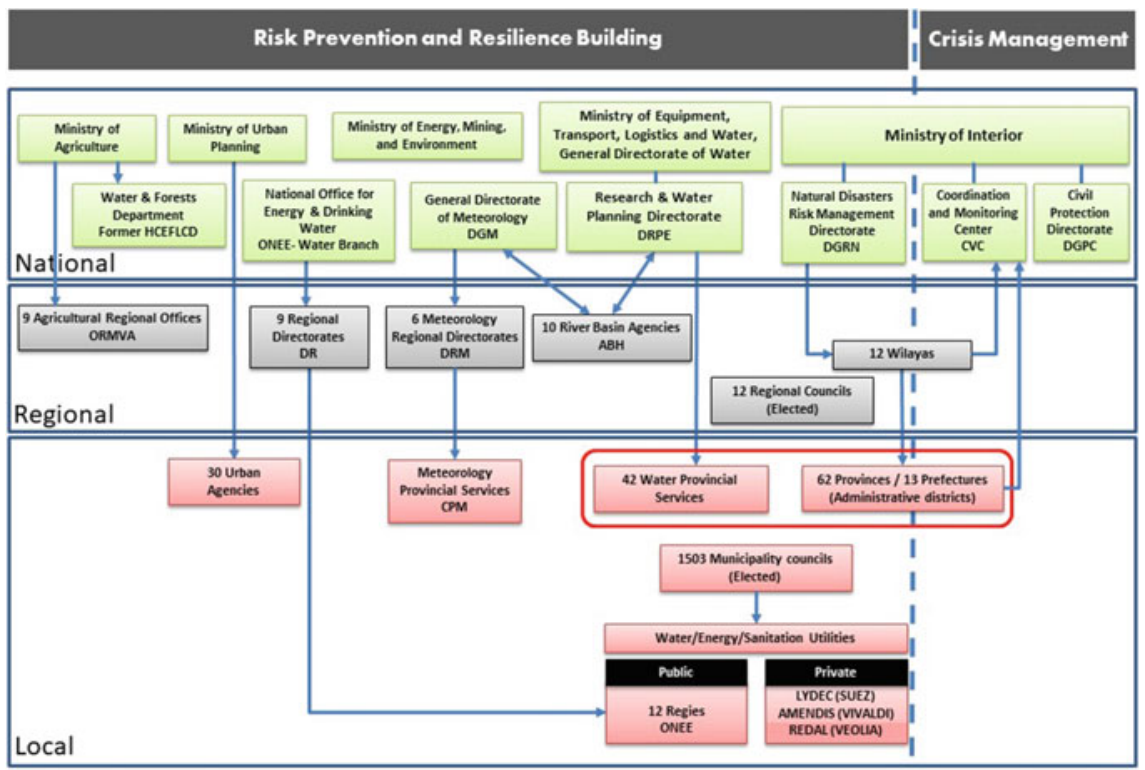

Fig. 2.8 Flood risk management institutional stakeholders in Morocco

water resources management including extreme events of droughts and floods management. The DRPE has always been involved in flood risk assessment and mitigation in addition to administrative support and coordination at national level for regional river basin agencies, namely ABHs. Of note, since 1992, the water department shifted jurisdiction between different ministries such as Ministry of Agriculture, Ministry of Equipment, Ministry of Land use Planning and Ministry of Energy, Mines and Environment. Since 2017, this department has been part of the Ministry of Equipment, Transport, Logistics and Water converted to the General Directorate of Water (DGE) since 2020. The DGE outlines the National Water Strategy, the National Water Plan, and the National Flood Protection Plan.

Ministry of Interior (MI): Natural disaster crisis management has always been handled by the Ministry of Interior. Later, the MI created the Monitoring and Coordination Center (CVC), in 2008, that oversees processes related to emergency situations and disaster crisis management. In particular, it leads decisions and actions relating to risk and threat prevention, coordination of disaster event operations, and recovery actions. The MI holds also the Civil Protection Directorate (DGPC) which is the official body carrying out operations on the ground when a disaster happens.

In 2020, the government created within the MI a central Directorate for Natural Disasters Risk Management (DGRN) to enhance efficient coordination between various and multi-level stakeholders. The DGRN is in charge of collecting information for optimizing operations during disaster events and crisis situations. This 
directorate is also responsible for the preparation of emergency plans, called ORSEC that are launched when disasters occur, including but not limited to floods.

Recently, the MI announced the creation of Flood Risk Management Center incorporating operational monitoring, warning, and assistance for flood management. The project is financed by the Fund to combat Effects of Natural Disasters (FLCN) that was created earlier in 2009. Initially, four pilot zones were targeted by this project for their flood history, namely Ourika valley, El Ghrab plain, Guelmim desertic area, and the coastal city of Mohammedia. A Provincial/Regional Coordination Center (PCC/RCC) will be installed in the administration representing the MI locally (Prefecture, Province or Region). The PCC/RCC will ensure coordination between the MI, the DGE, the General Directorate of Meteorology (DGM), the DRPE, the regional ABHs, and international organization partners.

General Directorate of Meteorology (DGM): It is an independent institution that is in charge of managing rainfall stations and meteorological radar networks throughout the Moroccan territory. Besides It has the responsibility of weather forecasting at national and regional levels, collecting, analyzing, and providing meteorological data, satellite images to different public and private operators.

Hydraulic Basin Agency (ABH): At catchment level, the river basin agency, called Hydraulic Basin Agency $(\mathrm{ABH})$ is the main regional water authority in Morocco. There are ten ABHs that cover all Moroccan watersheds. Each ABH coordinates its actions with the DGE within a collaborative approach for flood maps updates and flood control measures selection and adoption. The $\mathrm{ABH}$ has the responsibility of preparing the Master Plan for Integrated Water Resources Management including flood risk assessment, mitigation measures identification, and implementation of action plan in partnership with related stakeholders. The ABH also establishes Flood Atlas that identifies flood-prone areas within the catchment territory, manages its own hydrometeorological stations and flood warning networks, and performs its data monitoring and processing.

There are other ministries, institutions, and commissions that are involved in the management of flood risk either at assessment level or implementation of mitigation and adaptation measures level. For instance, the Ministry of Land Use and Urban Planning and its regional representations are in charge of including flood mapping in planning document. The former High Commissioner for Waters and Forests (HCEFLCD), now called Waters and Forests Department within the Ministry of Agriculture, is in charge of erosion control upstream, a serious problem that reduces the efficiency of flood control structural infrastructures (i.e. dams, dykes, drainage systems). The Ministry of Agriculture, the Department of Environment, water and sewerage utilities, and elected regional and local councils are other examples of stakeholders involved in flood control measures implementation.

\section{(b) Legal framework for flood risk management}

Water law 36-15: The DGE and ABHs carried out an assessment of the previous water law 10-95 enforcement in consultation with stakeholders and civil society. In the previous law 10-95, that prevailed for twenty years, only a section, under 
transitional provisions chapter, was dedicated to flood control. It provided weak framework limited to specific measures for flood and drought risks and regulated the implementation of measures for flood control. The study of this law revealed many shortcomings as it proved to be no longer adapted to the socio-economic changes of the Moroccan context. Among these shortcomings, weak provisions related to flood protection were highlighted. Therefore, the law needed to be updated to respond to the requirements of sustainable development and climate change conditions. In 2016, the new water law 36-15 was adopted. Flood provisions within this law were introduced as a legal measure to respond to national and international organizations call to adopt a new proactive approach for flood risk management in Morocco. As a result, this law is the first one to dedicate a whole chapter to floods. It gives provisions regarding (1) protection and flood risks prevention, (2) flood sensing, monitoring and warning, and (3) flood event management. The new water law 36-15 brought more specifications on the roles of stakeholders and diverse provisions on tools for flood risk management. Yet, this law states the obligation of addressing risk assessment through the production of flood Atlas by each $\mathrm{ABH}$. The flood Atlas aims at identifying flood-prone areas according to three levels of flood risk (low, medium, and high) and possibly indicating flood hazard frequencies. For high and medium flood risk areas, the law states the obligation of preparing Flood Risk Prevention Plan within a participatory approach involving others public stakeholders for the plan implementation. These plans are established for a twenty years period and can be revised as necessary.

So far, some ABHs have produced their flood Atlas whereas others have made progress on projects for local mapping of flood-prone zones in order to establish their own flood Atlas.

Another novelty of the water law 36-15 is the introduction of Integrated Systems for Flood Monitoring and Warning as a responsibility of each ABH. It should be fulfilled in cooperation with the DGM for data exchange. These systems contain rainfall-runoff models that allow the follow up of hydrological situation and flood risk prevention.

Insurance law 110-14 amending insurance code and establishing coverage scheme of disaster events: Following the recommendations of the World Bank, Morocco adopted in 2016 the new law 110-14 amending the Insurance Code to introduce a new coverage scheme of disaster events consequences. This law was first effectively implemented on 2020 as a financial measure to increase territories resilience to disasters including flood events. The new law also established the Fund of Solidarity against Catastrophic Events (FSEC) to allow compensation for victims of disaster events whether they are natural or man-made hazards.

\section{(c) Strategy and plans}

National Water Strategy (SNE): In 2009, the National Water Strategy (SNE) was established as a framework for implementing water action plans to respond to water demand under climate change and increasing constraints, in a sustainable manner 
for the 2010-2030 period (SNE 2009). The SNE is structured around the following six axes: (1) demand management and water resources recovery, (2) supply management and water availability development, (3) water resources protection and conservation (4) mitigation of vulnerability to water-related risks and adaptation to climate change, (5) regulatory and institutional reforms advancement and (6) upgrading Information Systems and capacity and resources building. Within the fourth axis, the SNE outlines actions for improving protection of people and property against floods through the following actions:

- finalizing actions described in the National Flood Protection Plan aiming at protecting vulnerable sites each year;

- integrating flood risk in land use planning, urban planning, and catchment management plan;

- improving knowledge in the field of weather forecasting and urban hydrology;

- developing flood warning systems and emergency plans; and

- developing financial mechanisms (i.e. insurance and natural disaster funds).

For the fulfillment of Morocco dam's policy, the SNE also sets the objective of building about sixty large dams by 2030 with a total storage capacity of 7 Billion $\mathrm{m}^{3}$. These dams have to meet the needs of water demand and flood control. The strategy aims also at building one thousand small and medium-sized dams by 2030 in order to support irrigation development, provide livestock water and protect against flooding. Another flood measure outlined in the SNE is rainwater harvesting by setting up pilot projects at small scale in each catchment before extending it to a larger regional scale.

National Flood Protection Plan (PNI): Following the 1995 Gharb plain floods that endangered national food security, and their successive recurrence, the DGE released the National Flood protection Plan in 2002, commonly called PNI (2002). The plan was aimed at reducing flood risk through (1) a detailed diagnostic of flood events, (2) an analysis of current institutional framework and suggestions for improving it, and (3) proposal of an action plan, its content, funding, cost, timetable, and implementation.

The PNI drew up an inventory of around 400 flood-prone sites, which were subject of consultation at the level of the ABHs along with various public departments. Within the framework of a partnership with the relevant parties, in particular the MI, the DGE started in 2003 the implementation of the PNI outcomes. One hundred sites were hence concerned with flood control measures by building small dams and developing watercourses.

Due to increasing flood events frequency, the DGE realized in 2010 an update of the PNI to include new flood-prone sites to reach a total of 1032 sites based on field visits (Fig. 2.9). A second update of the PNI is being currently undergone by the DGE and should be released shortly. The new PNI aims at drawing up a progress report on vulnerable sites processing and updating data and information regarding flood black points and flood control action plans (DRPE 2019). 


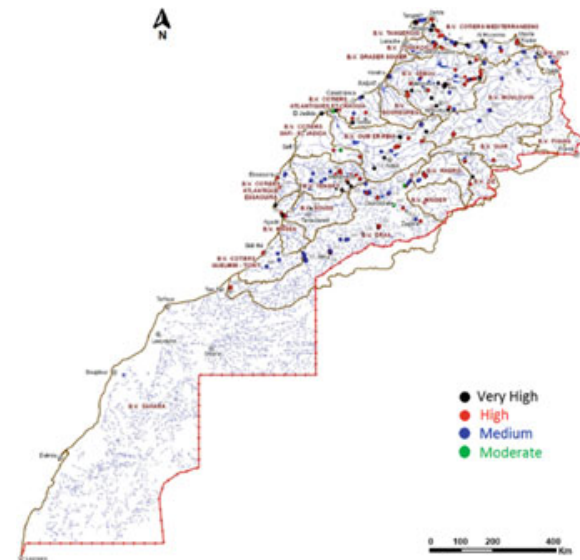

a)

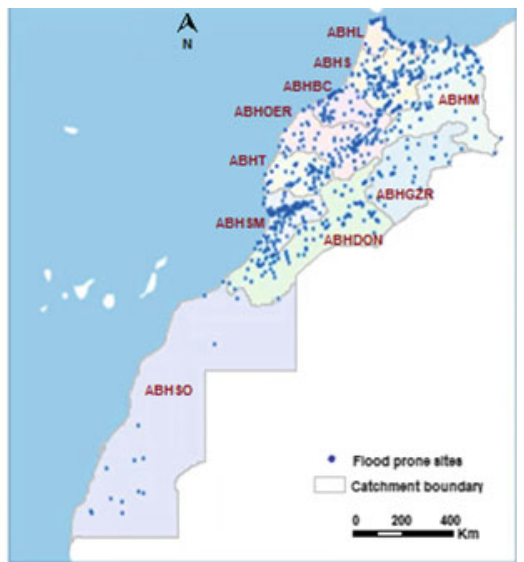

b)

Fig. 2.9 Flood-prone zones according to a PNI 2002; b PNI 2010 (Source PNI 2002, 2010)

National Water Plan (PNE): The National Water Plan, commonly called in Morocco PNE, was developed in 2015 by the DGE, formerly part of the Ministry of Energy and Mines. The plan draws up an inventory of water resources, presents the main directions of water policy, sets the plan of actions to be undertaken in the medium and long terms, the accompanying measures as well as a plan for their monitoring and financing. These actions relate to water demand management and development of water resources, water supply management and development, protection of water resources and the natural environment, and adaptation to climate change along with support actions (PNE 2015). The PNE used to be established for a period of at least twenty years. It could be subject to periodic reviews every five years and whenever exceptional circumstances required its update. The recent water law 36-15 has extended the PNE planning period horizon to thirty years and its update to ten years.

With regard to flood risk, the PNE gives orientations about action plan for flood control including structural and non-structural measures. To mitigate floods harmful impacts, structural actions to be taken related to the continued implementation of the PNI recommended control measures and their updates according to the current PNI update study carried out by the DGE. The PNE underlines the implementation of non-structural actions based on the following main provisions:

- reform of the legislative framework governing the management of flood risk;

- delineation of areas at flood risk and the establishment of flood risk maps by ABHs;

- articulation of planning and land use documents in order to control land use in areas at flood risk; 
- strengthening prevention by improving knowledge in the field of hydrometeorological forecasting and the development of flood forecasting, and emergency plans;

- development and strengthening of financial mechanisms (insurance and funds for natural disasters), consultation, and coordination.

Master Plan for Integrated Water Resources Management (PDAIRE): Each of the ten ABHs is required, under the previous and the current water laws, to elaborate its Master Plan for Integrated Water Resources Management, commonly called in Morocco PDAIRE. This plan is a road map for regional water resources management at catchment level for the next thirty years. It can be revised every ten years unless exceptional circumstances occurrence requires its amendment before this deadline. Its main objective is to respond quantitatively and qualitatively to current and future water demands of various users in the $\mathrm{ABH}$ catchment area. With regard to flood, one of the plan objectives is to assess flood risk within the basin in order to develop a regional strategy in a holistic approach that is consistent with the PNI, and contributes to the implementation of the SNE 2010-2030 directives along with the PNE 2020-2050. The PDAIRE presents a diagnosis of flood risk in its territory, and its action plan for flood control including program of structural and non-structural measures for flood mitigation, capital cost, funding plan, and timeline for implementing the selected measures. The PDAIRE also establishes limits of banned areas for any development that may disturb floodwater flow. To do so, the $\mathrm{ABH}$ conducts studies for identifying flood-prone areas, and priority sites for mitigation measures. The studies can be conducted using ABH's own resources or within contracts with consultant companies using the tender process. The first PDAIREs were developed in late eighties. Following the enforcement of water law 10-95 and later on law 36-15, many of the ABHs have updated or are in the process of updating their PDAIRE as stated by water law and its related regulations.

Within this framework, many other flood control studies and atlases of flood-prone zones were developed by the ABHs at local and regional levels. Accordingly, all flood black spots in each catchment were identified, and actions plans and partnerships were established. Hence, the PDAIRE is an important tool for updating the PNE, the National Urban Development Plan and the National Land use Plan in a bottom-up approach building national policies on the basis of regional level feedbacks.

Emergency Response Plan (Plan ORSEC): The Emergency Response Plan, commonly called ORSEC, is a document drawn up at the level of each prefecture and province under the responsibility of the Wali or Governor. The plan fixes, in advance, the course of action to be followed for the organization of rescue and relief of population and property in the event of a disaster including floods. The ORSEC ensures unity of command, tasks assignments, and coordination of actions and means. It gives also a complete inventory of human and material resources likely to be mobilized if necessary. In the event of a disaster, the alert is triggered by the Wali/Governor who gives the ORSEC warning for crisis management. He informs 
in particular, the Cabinet of the Ministry of Interior and the General Directorate of Civil Protection.

Master Plan for Risk Analysis and Coverage (SDACR): This document is prepared by the regional, provincial and prefectural commands of Civil Protection that is the national body in charge of emergency actions and relief during a disaster event. The SDACR draws up an inventory of specific risks in the region that Civil Protection services must face. It determines also the objectives of coverage of these risks by civil protection services. This document has a real database related to risk management for a better preparation of major crisis situations likely to compromise citizens safety, health, and sanitation. It is also a basic technical reference allowing the General Directorate of Civil Protection (DGPC) to develop and plan investment in equipment, and necessary actions for crisis management.

National Strategy for Natural Disaster Risk Integrated Management: Following the recommendation of OECD (2019), Morocco is in the process of elaborating its National Strategy for Natural Disaster Risk Integrated Management with the support of the World Bank. This strategy will be built upon the following five areas of action: (1) strengthening the governance of natural risk management, (2) improving knowledge and assessment of natural risks, (3) building resilience and prevention of natural risks, (4) disaster prevention for rapid recovery and better reconstruction, and (5) promoting scientific research, international cooperation, and capacity building. These areas correspond to the country priorities as well as to international reference frameworks such as the OECD recommendation on critical risk governance (OECD 2014), and the Sendai framework for disaster risk reduction (UNISDR 2015). Its adoption will also establish a monitoring and evaluation framework to measure progress towards improving Morocco's resilience.

\subsection{Technical Aspects of Flood Risk Assessment Methods}

\subsubsection{The PNI Assessment Method}

The PNI is the only document dedicated to flood risk strategy at national level. It gives a better understanding of flood risk in the Moroccan territory through a classification of observed flood types and the identification of vulnerable sites. The PNI (2002) study defined about 400 most vulnerable sites to flood in Morocco (Fig. 2.9a). The methodology used in the PNI (2002) and 2010 for risk mapping is a matrix that crosses hazard and vulnerability. The various risk components, as internationally defined by UNESCO, recalling the definition of the Office of United Nations Disaster Relief Coordinator-UNDRO (Varnes 1984), are computed using the following expression: 


$$
R_{t}=H_{t} \times V \times E
$$

in which: $R_{t}$ is the risk associated with a return period $t$ for the zones for which hydraulic models have been performed; $H_{t}$ represents the hazard associated with a return period $t$ over a given space; $E$ is the element at risk (person or asset exposed to the risk when the hazard $H_{t}$ occurs) on a given area and $V$ is vulnerability defined as the potential for the element at risk $E$ to undergo $H_{t}$ hazard. In this method, vulnerability $V$ is considered as the average damage that element $E$ can suffer when it is exposed to the hazard $H_{t}$.

(a) Flood hazard in Morocco has been described through two main components: average velocity and average height in wadis floodplains. The maximum daily precipitation maps were drawn up from the results of statistical adjustment (Gumbel distribution) of the 375 rainfall gauging stations of the ABHs (PNI 2002). GIS was used to represent the maximum daily precipitation values of these 375 positions for return periods of $10,25,50$, and 100 years in all watersheds. Therefore, mean runoff depths were extracted for each sub-basin related to each of the above return periods using an Inverse Distance Weighted (I.D.W.) interpolation method.

The 390 sites identified in the PNI (2002) study were ranked in five categories describing the hydraulic type of site flooding. This classification was based on the cause of flooding, the morphology of the site, and the availability of topographic data. Hydraulic calculations were then adapted to each category.

The maximum daily runoff depth was calculated for 10-year return period, for all the ABHs, based on data collected from 150 hydrometric stations, using probabilistic approaches such as the Gradex method and has also been mapped across the Moroccan territory. Hydraulic modeling was generally performed using HEC-RAS software. However, these models have only been carried out for sites with available topography maps at the scale $1 / 5000$ or $1 / 2000$ before 2002 . For sites with sparse data and coarse topographic map, the experts referred to the testimony of residents as a first approach for hazard assessment. For small watersheds with time of concentration of one hour or less, daily precipitation measurements were not representative of the rainfall intensity variation. The Montana equation, largely used in Morocco, was applied to daily rainfall to extract rainfall for shorter periods using the expression:

$$
I(t, T)=a(T) \times t^{b(t)}
$$

where $I$ is the mean rainfall intensity for a duration $t$ and a return period $T, a$ and $b$ are regional parameters calculated using statistical methods. In 2002, the flood assessment study was carried out despite the absence of long-period consecutive daily runoff measures for large catchments, and complete hydrographs for small watersheds. In order to reconstruct missing hydrologic data, such as peak flows or flood hydrographs in the flood-prone and ungauged sites, the maximum daily 
rainfall for a return period is computed as well as the rainfall for the same return period for a duration equal to 3 times the watershed concentration time. The Soil Conservation Service Curve Number SCS-CN is used for rainfall-runoff modeling.

The resulting hazard maps showed that the most important hazards were found on the Rif mountains, the Mediterranean coastal watersheds within the Loukkos catchment, and Sebou sub-basins with parts laying on the Rif mountains. On the Atlas Mountains, either on the upper basin of the Oum Er Rbia or on the upper Tensift catchments, maximum daily precipitation and runoff were less significant, which does not mean that flood risk was lower, especially on the Tensift basin. Indeed, daily rainfall values did not correctly translate the hourly intensities which can occur in these parts of the country, especially during summer thunderstorms, as they were very poorly measured by the rain gauging network in place. The hazard was then classified into four categories as shown in Table 2.2.

(b) Flood vulnerability was evaluated in a qualitative manner with regard to the importance and type of assets as shown in Table 2.3.

Flood risk was then assessed as a combination of hazard and vulnerability previous classifications. A matrix for flood risk classification was developed using five levels of risk, ranging from low risk to very high risk (Table 2.4). Example of hazard and risk maps developed in the PNI is shown in Fig. 2.10 for El Gara town, southeast Casablanca city in Morocco.

The level classes remain qualitative so that experts who have visited the sites can inform these classes even if they do not have concise data (calculations, reports) related to the strongest events recorded in recent years. Hence, another risk assessment approach was adopted in the PNI for sites where calculations were not made and flood hazard was assessed following residents' testimony. Six exposure categories were considered: Human exposure (H), Constructions/buildings (C), Infrastructures (I), Agriculture (A), Environment (Ev), and Economy (Ec). They correspond to the categories most often encountered on Moroccan territory, although it is extremely rare that only one is encountered at a given site. However, they have the advantage of paving the way to estimating the damage and assigning an economic value to the damage (Table 2.5).

For mapping purpose at national level, and for all type of assessment methods, only four types of risk were used. Thus Construction (C), Infrastructure (I) and

Table 2.2 Hazard classification in the PNI (2002)

\begin{tabular}{l|l|l|l|l}
\hline \multirow{2}{*}{ Velocity $(\mathrm{m} / \mathrm{s})$} & \multicolumn{4}{l}{ Height $(\mathrm{m})$} \\
\cline { 2 - 5 } & $<0.3$ & $0.30-0.80$ & $0.80-1.50$ & $>1.50$ \\
\hline$<0.50$ & LH & MH & HH & HH \\
\hline $0.50-1.00$ & MH & MH & HH & VHH \\
\hline $1.00-2.00$ & HH & HH & VHH & VHH \\
\hline$>2.00$ & HH & VHH & VHH & VHH \\
\hline
\end{tabular}

Source PNI (2002)

$L H$ Low Hazard, $M H$ Medium Hazard, $H H$ High Hazard, $V H H$ Very High Hazard 
Table 2.3 Vulnerability classification used in the PNI (2002)

\begin{tabular}{|c|c|c|}
\hline Low vulnerability (LV) & $\begin{array}{l}\text { - Desert areas } \\
\text { - Brownfields }\end{array}$ & $\begin{array}{l}\text { - Forest areas } \\
\text { - Natural areas }\end{array}$ \\
\hline Medium vulnerability (MV) & $\begin{array}{l}\text { - Extensive agricultural areas } \\
\text { - Arable lands }\end{array}$ & $\begin{array}{l}\text { - Secondary infrastructure } \\
\text { - Household landfills }\end{array}$ \\
\hline High Vulnerability (HV) & $\begin{array}{l}\text { - Intensive agricultural areas } \\
\text { - Irrigated agricultural areas } \\
\text { - Vegetable and fruit crops } \\
\text { areas } \\
\text { - Palm groves }\end{array}$ & $\begin{array}{l}\text { - Sparsely populated areas } \\
\text { - Low activity areas } \\
\text { - Main infrastructure } \\
\text { - Non-toxic industrial } \\
\text { landfills }\end{array}$ \\
\hline $\begin{array}{l}\text { Very High Vulnerability } \\
\text { (VHV) }\end{array}$ & $\begin{array}{l}\text { - Heavily populated areas } \\
\text { - Important activity areas } \\
\text { - Highly touristic areas }\end{array}$ & $\begin{array}{l}\text { - Camping sites } \\
\text { - Toxic industrial landfills }\end{array}$ \\
\hline
\end{tabular}

Source PNI (2002)

Table 2.4 Risk classification used in the PNI (2002)

\begin{tabular}{l|l|l|l|l}
\hline \multirow{2}{*}{ Vulnerability } & \multicolumn{4}{l}{ Hazard } \\
\cline { 2 - 5 } & LH & MH & HH & VHH \\
\hline LV & LR & LR & MR & MR \\
\hline MV & LR & MR & MR & HR \\
\hline HV & MR & HR & VHR & VHR \\
\hline VHV & MR & VHR & VHR & EHR \\
\hline
\end{tabular}

Source PNI (2002)

$L R$ Low Risk, $M R$ Medium Risk, $H R$ High Risk, $V H R$ Very High Risk, EHR Exceptional High Risk

Agricultural (A) risks were grouped under a same section called "Social Risk" (S). The highest risk of these three categories gives the degree of social risk ( $\mathrm{S}=\mathrm{Max}$ $[\mathrm{C}, \mathrm{I}, \mathrm{A}])$.

A five level Global Risk (GR) index was defined as a quantitative value assigned for each risk category as follows:

If $\operatorname{Max}(\mathrm{H}, \mathrm{S}, \mathrm{Ev}, \mathrm{Ec})=0 \rightarrow \mathrm{GR}=0$-Minor

If $\operatorname{Max}(\mathrm{H}, \mathrm{S}, \mathrm{Ev}, \mathrm{Ec})>0$ :

If $\operatorname{Max}(\mathrm{H}+1, \mathrm{~S}, \mathrm{Ev}, \mathrm{Ec})=1 \rightarrow \mathrm{GR}=1-$ Low

If $\operatorname{Max}(\mathrm{H}+1, \mathrm{~S}, \mathrm{Ev}, \mathrm{Ec})=2 \rightarrow \mathrm{GR}=2-$ Medium

If $\operatorname{Max}(\mathrm{H}+1, \mathrm{~S}, \mathrm{Ev}, \mathrm{Ec})=3 \rightarrow \mathrm{GR}=3$ - High

If $\operatorname{Max}(\mathrm{H}+1, \mathrm{~S}, \mathrm{Ev}, \mathrm{Ec})=4 \rightarrow \mathrm{GR}=4$-Very high

Consequently, a Global Risk cannot be low unless there is no human risk $(\mathrm{H}=0)$. An example of the GIS-based map built upon these considerations is shown in Fig. 2.11.

In order to better rank quantitatively each of the flood-prone sites with regard to the importance of their risk exposure, the following scores were assigned to each of the risk levels: 


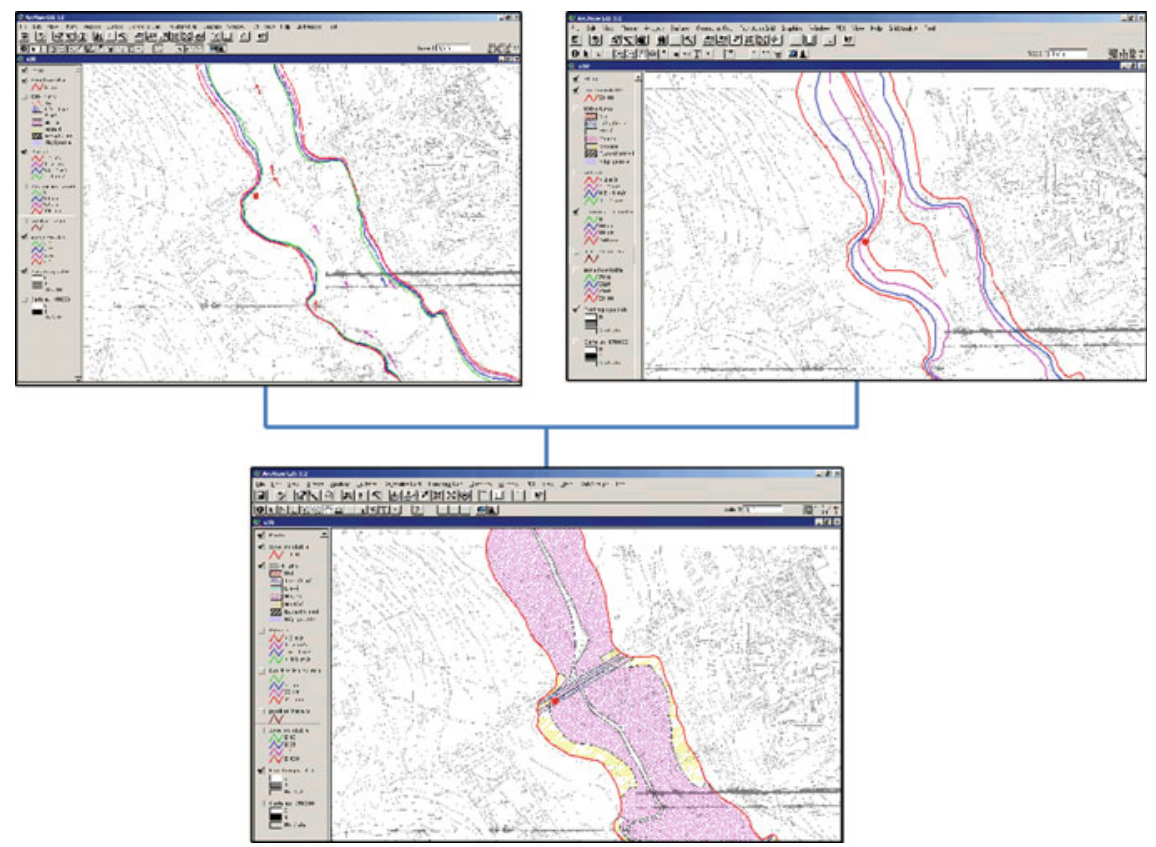

Fig. 2.10 Example of flood maps developed in PNI, case of El Gara town site a hazard map and velocities, b flood depths map, c flood risk map (Source PNI 2002)

1 for low risk; 2 for medium risk; 3 for high risk; 5 for very high risk and weight coefficients for each of the different types of risk:

Human risk (H): 10; Construction risk (C): 7; Infrastructure risk (I): 7; Agricultural Risk (A): 6; Environmental Risk (Ev): 8

The Economic risk $(\mathrm{Ec})$ was not taken into account directly because it is not independent of other risks. It is in fact strongly linked to them and it is rather through the sum of the weighted ratings assigned to each site that an idea on the importance of the economic risk can be made. In the 2010 PNI update, economic criteria were discarded as it is very subjective and time-dependent value.

Using these assessment criteria for each category $(\mathrm{H}, \mathrm{C}, \mathrm{I}, \mathrm{A}, \mathrm{Ev}, \mathrm{Ec})$ and assigned weighting coefficients, the 391 sites were ranked downward according to their scores in PNI (2002). This ranking allowed to identify 50 most priority sites to be protected against flood risk in Morocco and therefore to facilitate the elaboration of investment plans at national and regional levels.

In the first method, hazard (i.e. height and velocity) assessment approach was probabilistic and therefore risk assessment was also probabilistic within certain limits of simplification as certain vulnerability elements are variables (e.g. disaster arriving day or night, a weekday or a holiday, house inhabited or not during the 
Table 2.5 Categories of exposure and their classification

\begin{tabular}{|c|c|c|c|c|}
\hline \multirow[t]{2}{*}{ Nature } & \multicolumn{4}{|l|}{ Level } \\
\hline & Low & Medium & High & Very high \\
\hline Human: H & $\begin{array}{l}\text { Risk of injuries } \\
\text { - Isolated } \\
\text { persons for } \\
\text { long-duration } \\
\text { flood }\end{array}$ & $\begin{array}{l}\text { Risk of victims } \\
\text { ( } 1 \text { to } 10 \\
\text { victims) }\end{array}$ & $\begin{array}{l}\text { Risk of victims } \\
\text { ( } 10 \text { to } 50 \\
\text { victims) }\end{array}$ & $\begin{array}{l}\text { Risk of victims } \\
\text { (more than } 50 \\
\text { victims) }\end{array}$ \\
\hline Constructions: C & $\begin{array}{l}\text { Less than } \\
50 \mathrm{~cm} \text { flood } \\
\text { heights and less } \\
\text { than } 50 \text { affected } \\
\text { dwellings with } \\
\text { little or no } \\
\text { damage }\end{array}$ & $\begin{array}{l}\text { Less than } \\
50 \mathrm{~cm} \text { flood } \\
\text { heights with } \\
\text { more than } 50 \\
\text { affected } \\
\text { dwellings Or } \\
\text { more than } \\
50 \mathrm{~cm} \text { flood } \\
\text { heights with } \\
\text { less than } 50 \\
\text { affected } \\
\text { dwellings and } \\
\text { moderate } \\
\text { damage }\end{array}$ & $\begin{array}{l}\text { Flood heights } \\
\text { between } 50 \mathrm{~cm} \\
\text { and } 1 \mathrm{~m} \text { with } \\
\text { houses and } \\
\text { assets damaged }\end{array}$ & $\begin{array}{l}\text { More than } 1 \mathrm{~m} \text { flood } \\
\text { heights-destroyed } \\
\text { houses }\end{array}$ \\
\hline Infrastructures: I & $\begin{array}{l}\text { Roads } \\
\text { (secondary } \\
\text { roads-paths- } \\
\text { streets) flooded } \\
\text { for a short time } \\
\text { with less than } \\
20 \mathrm{~cm} \text { flood } \\
\text { height-no } \\
\text { damage }\end{array}$ & $\begin{array}{l}\text { Roads (main/ } \\
\text { secondary } \\
\text { roads - paths- } \\
\text { streets) flooded } \\
\text { with flood } \\
\text { height between } \\
20 \text { and } 50 \mathrm{~cm} \\
\text { with traffic } \\
\text { interrupted for } \\
\text { few hours- } \\
\text { low structure } \\
\text { damages }\end{array}$ & $\begin{array}{l}\text { Roads and } \\
\text { bridges flooded } \\
\text { with more than } \\
50 \mathrm{~cm} \text { flood } \\
\text { heights; traffic } \\
\text { interrupted for } \\
\text { few hours to } \\
\text { few days. } \\
\text { Significant } \\
\text { structure } \\
\text { damages }\end{array}$ & $\begin{array}{l}\text { Roads and bridges } \\
\text { flooded with more } \\
\text { than } 1 \mathrm{~m} \text { flood } \\
\text { heights. Destroyed } \\
\text { structures, traffic } \\
\text { interrupted for few } \\
\text { days to few weeks. } \\
\text { Dykes and networks } \\
\text { (water, energy, and } \\
\text { telecommunication) } \\
\text { heavily damaged } \\
\text { with distribution } \\
\text { service interruption } \\
\text { for many days }\end{array}$ \\
\hline Agricultural: A & $\begin{array}{l}\text { Flooding of } \\
\text { meadows, } \\
\text { forest areas, } \\
\text { and small } \\
\text { extensive } \\
\text { agricultural } \\
\text { areas-little or } \\
\text { no damage }\end{array}$ & $\begin{array}{l}\text { Flooding of } \\
\text { large extensive } \\
\text { agricultural } \\
\text { areas and small } \\
\text { intensive } \\
\text { agricultural } \\
\text { areas_average } \\
\text { damage }\end{array}$ & $\begin{array}{l}\text { Flooding of } \\
\text { large intensive } \\
\text { agricultural } \\
\text { areas and } \\
\text { medium } \\
\text { irrigated areas } \\
\text { - significant } \\
\text { damage to soil, } \\
\text { crops, and } \\
\text { structures }\end{array}$ & $\begin{array}{l}\text { Flooding of } \\
\text { intensive } \\
\text { agricultural areas or } \\
\text { agricultural areas } \\
\text { with high crops } \\
\text { added value and } \\
\text { high local economic } \\
\text { impact (fruit-palm } \\
\text { groves) } \\
\text { Very significant } \\
\text { damages- } \\
\text { infrastructure } \\
\text { destroyed- } \\
\text { plantation losses- } \\
\text { erosion or } \\
\text { significant soil } \\
\text { sedimentation }\end{array}$ \\
\hline
\end{tabular}


Table 2.5 (continued)

\begin{tabular}{|c|c|c|c|c|}
\hline \multirow[t]{2}{*}{ Nature } & \multicolumn{4}{|l|}{ Level } \\
\hline & Low & Medium & High & Very high \\
\hline Economic: Ec & $\begin{array}{l}\text { Some recovery } \\
\text { actions (street } \\
\text { sweeping- } \\
\text { sediment } \\
\text { removal- } \\
\text { washing } \\
\text { carpets-floors } \\
\text { —walls- } \\
\text { paintings, etc.) } \\
\text { Less than } \\
\text { MAD 100,000 } \\
\text { damage cost }\end{array}$ & $\begin{array}{l}\text { Damages cost } \\
\text { (private and } \\
\text { public) } \\
\text { comprised } \\
\text { between MAD } \\
100,000 \text { and } \\
\text { MAD } \\
1,000,000\end{array}$ & $\begin{array}{l}\text { Direct and } \\
\text { indirect } \\
\text { damages cost } \\
\text { (Job losses- } \\
\text { rescue } \\
\text { operations-- } \\
\text { relocation- } \\
\text { medical and } \\
\text { social } \\
\text { assistance) } \\
\text { comprised } \\
\text { between MAD } \\
1,000,000 \text { and } \\
\text { MAD } \\
10,000,000\end{array}$ & $\begin{array}{l}\text { Direct and indirect } \\
\text { damages cost higher } \\
\text { than MAD } \\
10,000,000 \mathrm{Dh}\end{array}$ \\
\hline $\begin{array}{l}\text { Environmental: } \\
\text { Ev }\end{array}$ & $\begin{array}{l}\text { Return to the } \\
\text { river of floating } \\
\text { bodies, traces } \\
\text { of oil products } \\
\text { washed out by } \\
\text { flood from the } \\
\text { pavements } \\
\text { washed, } \\
\text { fertilizer } \\
\text { agricultural }\end{array}$ & $\begin{array}{l}\text { Vulnerable } \\
\text { zones } \\
\text { (wetlands) } \\
\text { flooded and } \\
\text { polluted }\end{array}$ & $\begin{array}{l}\text { Spill in the } \\
\text { natural } \\
\text { environment } \\
\text { (streams- } \\
\text { lakes-ponds } \\
\text { - reservoirs) } \\
\text { common toxic } \\
\text { products } \\
\text { harmful to } \\
\text { flora, fauna and } \\
\text { exceeding } \\
\text { sanitary } \\
\text { standards for } \\
\text { water intended } \\
\text { for human } \\
\text { consumption }\end{array}$ & $\begin{array}{l}\text { Spill in the natural } \\
\text { environment of } \\
\text { highly toxic } \\
\text { products which can } \\
\text { destroy partially or } \\
\text { totally the flora and } \\
\text { fauna and cause a } \\
\text { break in } \\
\text { consumption of } \\
\text { water for domestic } \\
\text { use }\end{array}$ \\
\hline
\end{tabular}

Source PNI (2002)

$M A D$ Moroccan Dirham (10 MAD is about 1 USD)

event). Yet, in the second method, more simplified, the risk is no longer probabilistic but rather refers to the most significant event observed in recent years. Given the current level of investigation, this approach is yet sufficient to properly identify the areas at greatest risk and to undertake a prioritization of actions. Other international bodies, such as the World Bank, Euro-Mediterranean Partnership, and UNDP, also carried out studies about flood risks in Morocco (WB 2011a, b; SEEE/ UNDP 2008; SEEE 2008; EMWIS 2005). These disparate studies came up with interesting results and solutions but in either very broad or fragmented way. 


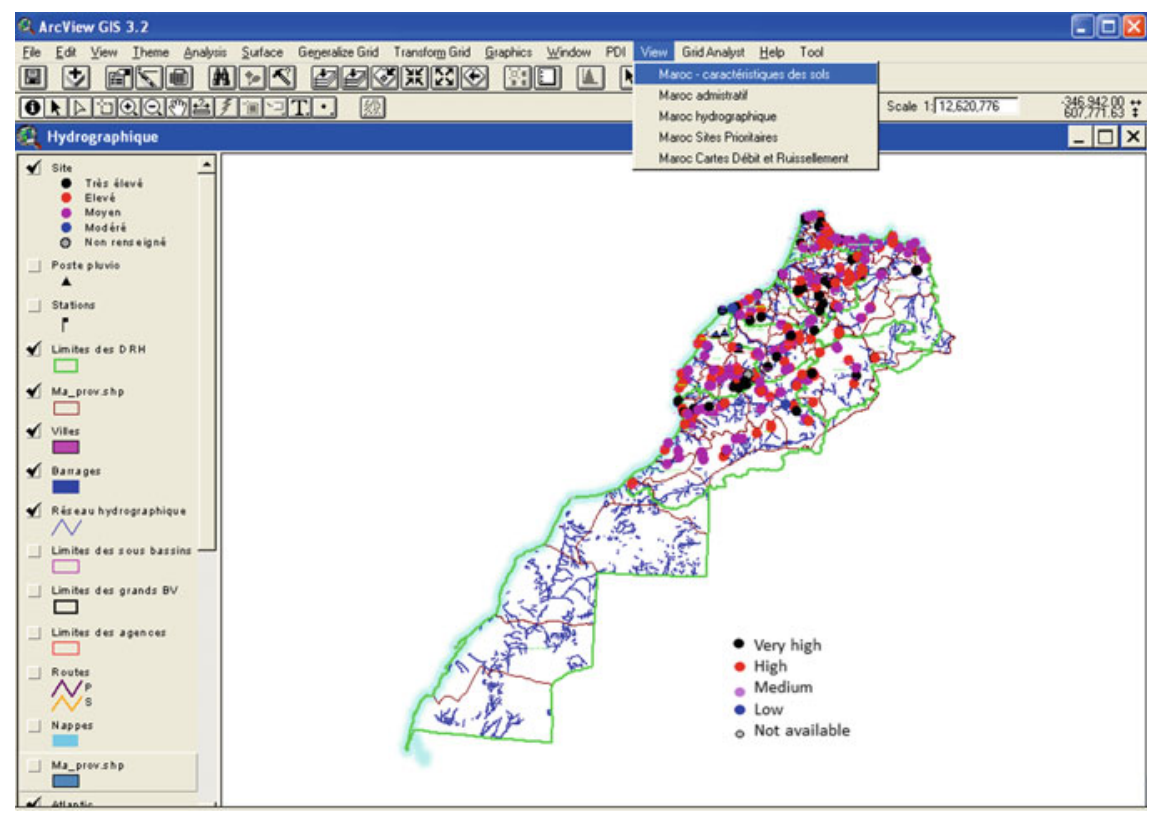

Fig. 2.11 Overview of GIS database output map for flood risk assessment developed in PNI 2002 (Source PNI 2002)

\subsubsection{The PDAIRE Method}

As mentioned in Sect. 2.3.2c, each ABH prepares its Master Plan for Integrated Water Resources Management (PDAIRE) that has to include a component on 'Flood protection', describing flood related-actions carried out by each ABH since 2002 and offering more concise details of outlined measures than the PNI.

Most ABHs have led their field investigation to identify prone flood areas within their territory to comply with the PDAIRE directives and to establish their Atlas of flood-prone zones as requested by water law 36-15 (e.g. Atlas of flood-prone areas of Tensift catchment, ABHT 2007). Based on information available on entire sections of valleys, the atlas of flood-prone zones consist of an informative map of historical flood events, hazard map (i.e. probability, extent, intensity) complemented by other information on the wadi beds geomorphology and floodplains exposure. The Atlas provides the basis for flood risk management as it is the main regional document that produces:

- Information for decision-makers of water planning and urban planning;

- Identification of vulnerability (e.g. housing, public services, economic activities, roads) subject to different hazards; and floodplains to be protected;

- Identification of flood mitigation measures. 
PDAIRE has considered a different way of hazard assessment. For example, in ABHBC (2007), floods where classified according to the time of rise $t_{r}$, which refers to time from the start of rainfall excess to the peak of the hydrograph. According to this classification, the sub-catchments of the basin were ranked as medium-rise floods or slow rise floods. The flood hazard in this catchment was assessed for six urban watersheds (Casablanca, Nfifekh, El Mellah, Bouskoura, Merzeg, and Bouregreg sub-basins catchments and Berrechid plain). Climate change parameters that were considered are (1) extreme precipitations: based upon daily precipitation data and new design storm of 10 to 100 year-return periods; and (2) sea level: to assess boundary conditions downstream of certain coastal streams and sewage systems. For flood hazard assessment in urban basin, design storms used for modeling the sewer networks are based on Intensity-Duration-Frequency (IDF) curves of observed rainfall at the Casablanca-Anfa station. The effect of climate change on stream discharges was evaluated using Gradex method, in consistence with the method used in the PDAIRE surface water resources assessment studies.

For vulnerability assessment, the ABHBC used the same methodology as in the PNI considering the six exposure criteria: Human exposure, Buildings, Infrastructures, Agriculture, Environment, and Economy. Five levels of risk ranging from minor risk to very high risk were defined accordingly. The output of this analysis is a map showing risk level for several parts of the basin (Fig. 2.12). This result gives an indication of the exposure of the catchment to different risk categories ranging from very high flood risk to low flood risk. Urban flood vulnerability of Casablanca city was analyzed using parameters such as density, building quality, number of floors and social level, economic activities. The current and 2030-future flood vulnerability maps were given based on extreme precipitation change (20022050). The same approach was used to assess flood risk in an urban planning touristic project in the city of Rabat (WB 2011a).

Other ABHs such as Sebou, Moulouya, Loukkos, have also led their studies for flood protection and suggested structural and non-structural measures that were later adopted within their PDAIRE and the PNI updating processes. Given the important cost of flood control measures, financial support of different public and private entities, and sometimes within international cooperation, are sought by the ABHs to implement these measures.

\subsubsection{The MnhPRA Assessment Method}

During the period 2010-2012, a project coordinated by the Moroccan Ministry of General Affairs and Governance, with the support of the World Bank, the Global Facility for Disaster Reduction and Recovery, and the Swiss Agency for Cooperation and Development, developed an open-source new GIS analysis tool called Morocco natural hazards Probabilistic Risk Analysis (MnhPRA) for disaster modeling. Using advanced probabilistic risk assessment approach, this program 


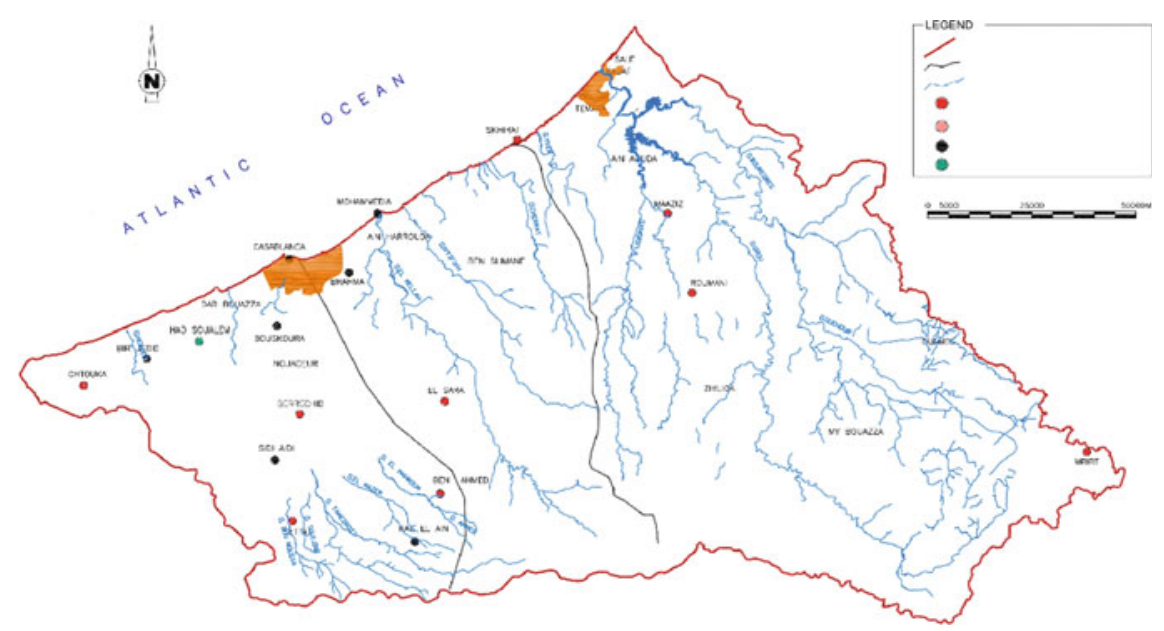

Fig. 2.12 Map of flood-prone zones and their different levels of risk in Bouregreg-Chaoui catchment (Source ABHBC 2007)

generates a detailed analysis of return periods on the basis of advanced risk models (Michel-Kerjan et al. 2014). MnhPRA is built upon four basic modules for disaster modeling that are hazard, inventory, vulnerability, and loss (Fig. 2.13):

- Module 1 (M1): The risk of the hazard phenomenon is calculated by first assessing the occurrence and frequency of events using a set of stochastic events, a set of simulated events characterizing observed or scientifically

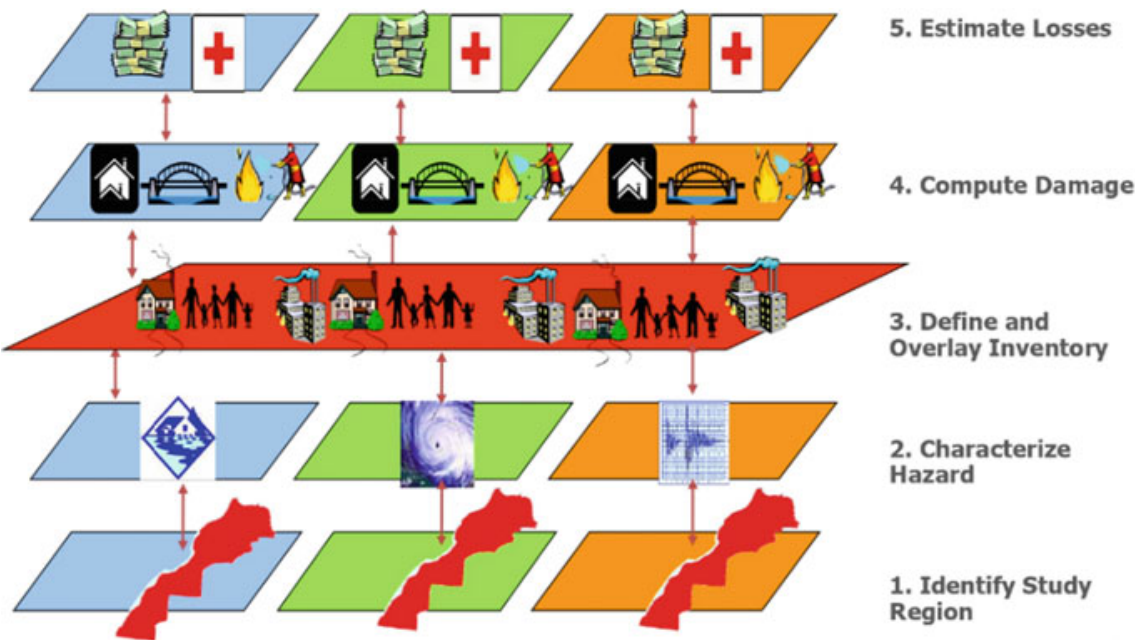

Fig. 2.13 MnhPRA risk analysis process (Source Scawthorn 2017) 
modeled events and their probability of occurrence. Secondly, the severity of events is calculated based on data of rainfall stations at each site of nine catchments that are: Loukkos, Sebou, Moulouya, Bouregreg and Chaouia, Tensift, Oum Er Rbia, Souss, Draa - Oued Noun, and Guir-Ziz-Gheris.

- Module 2 (M2): The inventory of assets at risk is characterized. The portfolio includes the entire built environment of Morocco (e.g. residential, commercial, industrial, public infrastructure). The inventory is based on a combination of data collection through field visits and satellite information.

- Module 3 (M3): Vulnerability is quantified to evaluate the way in which assets or infrastructures at risk identified in the inventory module (M2) will react physically under the events generated in risk module (M1). Vulnerability functions represent the relationships between the intensity of the risks (e.g. Flood depth) at the site and the level of damage.

- Module 4 (M4): Disaster losses are calculated assuming that the only uncertainty is the occurrence of an event. For example, the occurrence of floods in Casablanca follows a certain mathematical process which has been specified in the risk module at first, then its severity is calculated in the second part of the risk module (M1) across the whole city. Vulnerability module (M3) then calculates the average damage ratio at each site given the characteristics specified in the inventory module (M2). Finally, the loss module examines damages according to the values of exposure and calculates the total losses on this site producing a Loss Exceedance Curve (LEC) that gives the annual probability to a disaster aggregated loss to be exceeded yearly.

The tool provides also an economical estimation of flood damages using the Average Annual Loss (AAL) for any type of inventory for a selected hazard in a selected location. According to the analysis of risk assessment based on MnhPRA tool, in the next 20 years, there is a 95\% chance of flood in Morocco causing losses estimated at MAD 5 billion, and a $65 \%$ chance of an event causing losses of about MAD 25 billion. Floods remain fairly frequent and building losses are about $75 \%$ of the AAL (93\% in the case of earthquake and only 50\% in the case of tsunami).

MnhPRA can also assess potential flood mitigation measures, the best solution being the one which total cost is the lowest. The total cost is calculated as the sum of capital cost and damages cost.

Over forty flood risk mitigation scenarios were assessed using MnhPRA, based on a cost-benefit analysis (WB 2012). The measures range from flood warning systems to elevating buildings for protection against floods. The scenarios considered high-risk areas such as Kenitra province for floods. According to the MnhPRA based analysis, the highest Benefit-Cost-Ration (BCR) flood mitigation scenarios over Moroccan territory were:

- Flood warning system for Ouregha sub-basin $(\mathrm{BCR}=54.3)$

- Culverts on railway lines in Gharb plains $(B C R=34.6)$

- Mitigation of 46 residential buildings for floods in new township near Kenitra $(\mathrm{BCR}=8.2)$ 
- Mitigation of 47 government buildings for floods in new township near Kenitra $(\mathrm{BCR}=7.2)$

- Risk assessment for floods in new township near Kenitra $(\mathrm{BCR}=5.7)$

- Mitigation of school buildings for floods in new township near Kenitra $(\mathrm{BCR}=4.2)$

MnhPRA is the first tool that brought an economic analysis of flood measures in Morocco. The damage is calculated in a quantitative way, unlike the previous approaches, where damages were assessed in a qualitative manner. However, although this probabilistic model has been widely disseminated to the flood risk management stakeholders, in particular through organization of training sessions, it was noted that it is not used in almost all organizations visited by the Court of Auditors (Cour des comptes 2016). Except the Insurance and Social Security Regulatory Authority (called ACAPS) and few private insurances companies, MnhPRA model is not very widely used in particular within the flood risk management public stakeholders (e.g. ABHs, Urban planning agencies, etc.). Besides, till 2019, none of the regional administrations or provinces has developed a flood risk management integrated information system (WB 2019). The same year, the WB released a loan for Morocco to support the country in development of its National Strategy for Natural Disaster Risk Integrated Management with the objective of adopting it within 2020 calendar. One of the main expected outcomes of this strategy is to develop an Integrated Information System for Disaster Risk Management based on the adoption of cooperation framework to enhance flood risk management and early warning systems in the country.

\subsubsection{The OECD Approach}

In 2016, the OECD released a study on risk management policies in Morocco that has highlighted the country main advancements in this subject but also the main shortcomings of these policies (OECD 2016). The study made over thirty recommendations about the whole risk management cycle including, risk assessment, risk prevention, preparedness, emergency responses, and buildings. As a result, the Moroccan government, with the support of Swiss cooperation, asked the OECD to provide the necessary expertise for implementing these recommendations for the period 2017-2018. Hence, the OECD launched a capacity building program for local and national stakeholders about knowledge and risk assessment enhancement (OECD 2017a). The main outcome of these training was to raise the awareness of parties on the urgent need for: (1) the development of a shared GIS database from data institutions producers such as DGM, ABHs, Urban Planning Agencies, Wilayas as a common and integrated platform for national risk assessment; (2) capacity building in hydraulic modeling for ABHs and mapping tools for many parts of the Moroccan territory; (3) flood vulnerability atlas for all the ABHs based on hydrological modeling and high-resolution Digital Elevation Models 
(DEM) and/or satellite images and LiDAR in a consistent way with the GIS platform.

Within this framework, the OECD organized training sessions and produced a guide on knowledge and natural disaster risk assessment in Morocco (OECD 2018). The guide introduced the concept of exposure and thus defined the risk as:

\section{Risk $=$ Hazard $\times$ Vulnerability $\times$ Exposure}

- Hazard is defined by its intensity and frequency. Floods intensities with 50 and 100 years return period should be adopted.

- Vulnerability is ranked within four categories: Physical (e.g. Building quality) Human and social (e.g. elderly people, isolated and handicap peoples); Economical and financial (e.g. agriculture, tourism) and Environmental (e.g. natural resources). The same classification for vulnerability as in the FNP was adopted. Table 2.3 gives an example of vulnerability levels by economic zones.

- Exposure to the hazard is evaluated based on the relative importance of its components (humans, assets, economical activities, historical sites, etc.) such as the population density, assets, economical activities, historical sites, etc., and related threats.

- Risk is assessed by combining hazards and vulnerability analysis. It characterizes thus potential impacts of disasters on a given territory. This involves estimating these consequences and defining a risk classification scale according to their relative importance (Fig. 2.14).

In 2019, the OECD carried out an evaluation of risk management advances in Morocco since 2016 and concluded that knowledge of risks is progressing but remains insufficient. However, major progress on prevention with the Fund to combat Effects of Natural Disasters (FLCN) call for projects mechanism can be

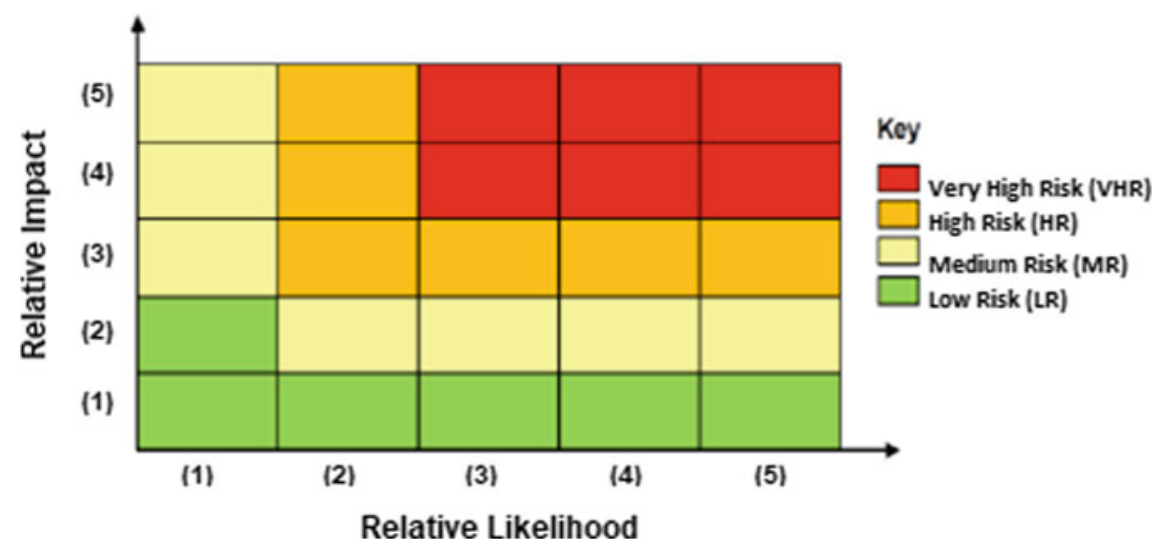

Fig. 2.14 Flood risk assessment matrix (Source OECD 2018) 
made. There is also a factual need to promote scientific research in the field of risk management and strengthen international cooperation.

\subsection{Flood Control Practices}

The PNI study (PNI 2002) had estimated the average cost of flood damages at USD 4.2 Million for each flooded site on average. Flood risk assessment over the Moroccan territory has revealed that about 400 sites were exposed and for which protection measures will require in total about USD 2.5 Billion. The plan has identified 50 priority sites using two types of flood control measures, namely structural and non-structural measures. Structural measures include:

- Cleaning operations, recalibration, widening of the wadis crossing structures (bridges, scuppers, culverts, etc.), construction of canals to regenerate the initial wadi corridor, riverbanks protection, damming of wadis, creation of peripheral water diversion canals, construction of dams or weirs for water storage and flood lamination upstream endangered areas, and

- Earthworks, demolition, bank protection, embankment, culverts-bridges-riffles-fords, dams, and related works.

Non-structural measures aim at mitigating floods by controlling vulnerability mainly through:

- Regulation of land use in flood-prone areas through delineation studies and raising public awareness against encroachment upon these areas; and

- Implementation of flood warning systems, maintenance of watercourses, development of watersheds, risk prevention rescue plan, monitoring systems, information, training, and participation.

The total investment cost of operations planned within this program for the shortlisted sites is USD 571.5 Million, in which $79 \%$ is dedicated to structural measures. Among these later, $34 \%$ of the investment cost is dedicated to dams.

\subsubsection{Dams for Flood Control}

Thanks to the dam's policy launched in late sixties, Morocco accounted for 145

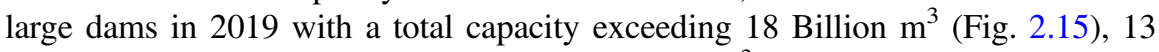
hydraulic water transfer structures (Flow rate: $200 \mathrm{~m}^{3} / \mathrm{s}$, Length $1100 \mathrm{~km}$, Volume 2.5 Billion $\mathrm{m}^{3} /$ year) and over a hundred small dams and reservoirs. Many of these dams are for flood protection (Table 2.6). Dams storage capacity will be increased in 2030 to 27 Billion $\mathrm{m}^{3}$ with the objective of building 2-3 large dams per year. The choice of dams is part of action plan for developing water supply, meeting local needs, and concurrently, protecting against floods. 


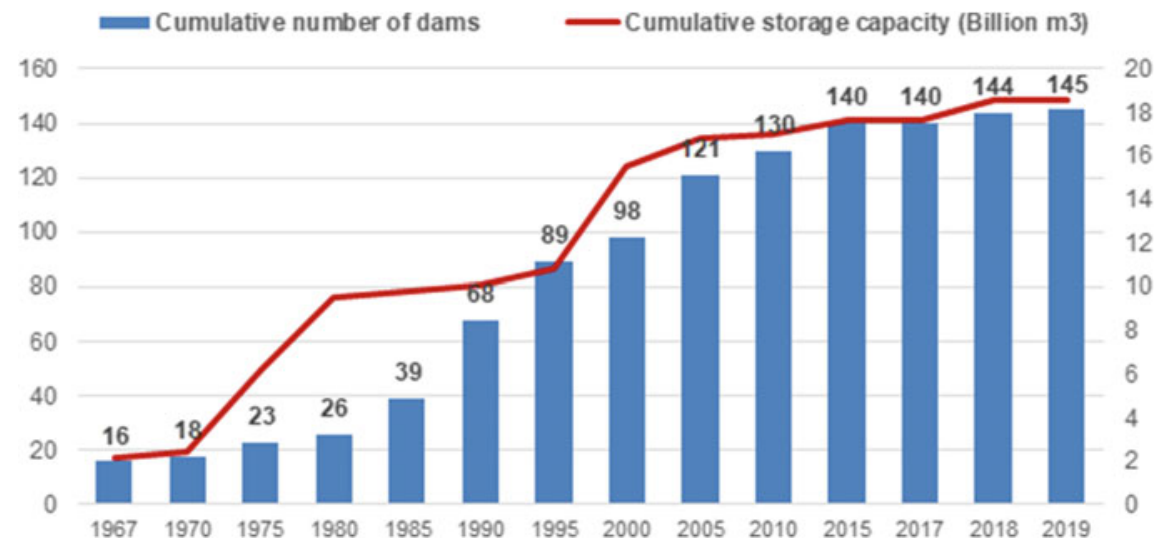

Fig. 2.15 Evolution of built large dams' number and their storage capacity 1967-2019 (Source DGE 2020)

Table 2.6 Main flood protection dams in Morocco

\begin{tabular}{|c|c|c|c|c|c|}
\hline Dam & Province & Year & $\begin{array}{l}\text { Height } \\
(\mathrm{m})\end{array}$ & $\begin{array}{l}\text { Storage } \\
\left(\mathrm{Mm}^{3}\right)\end{array}$ & Protected zone \\
\hline Mellah & $\begin{array}{l}\text { Ben } \\
\text { Slimane }\end{array}$ & 1931 & 33 & 8.8 & Mohammedia city \\
\hline El Knsera & Khemissat & 1935 & 68 & 266 & $\begin{array}{l}\text { Beht and Moghrane } \\
\text { agricultural area }\end{array}$ \\
\hline Mohamed V & Oujda & 1967 & 64 & 700 & $\begin{array}{l}\text { upstream zones } \\
\text { including Saidia port }\end{array}$ \\
\hline $\begin{array}{l}\text { Hassan } \\
\text { Addakhil }\end{array}$ & Errachidia & 1971 & 85 & 320 & Ziz valley \\
\hline $\begin{array}{l}\text { Mansour } \\
\text { Addahbi }\end{array}$ & Ouarzazate & 1972 & 70 & 529 & Draa valley \\
\hline Idriss 1er & Taounate & 1973 & 72 & 1186 & El Gharb plain \\
\hline $\begin{array}{l}\text { Sidi Med Ben } \\
\text { Abdallah }\end{array}$ & Rabat & 1974 & 99 & 1000 & Bouregreg valley \\
\hline $\begin{array}{l}\text { Oued El } \\
\text { Makhazine }\end{array}$ & Larache & 1979 & 67 & 773 & $\begin{array}{l}\text { Ksar El Kebir city and } \\
\text { Loukkos plain }\end{array}$ \\
\hline $\begin{array}{l}\text { Saquia El } \\
\text { Hamra }\end{array}$ & Laayoune & 1995 & 16 & 110 & Laayoune-Trafaya road \\
\hline Wahda & $\begin{array}{l}\text { Sidi } \\
\text { Kacem }\end{array}$ & 1996 & 88 & 3800 & El Gharb plain \\
\hline Hassan II & Midelt & 2000 & 91 & 275 & Moulouya upstream \\
\hline $\begin{array}{l}\text { Ahmed El } \\
\text { Hansali }\end{array}$ & $\begin{array}{l}\text { Béni } \\
\text { Mellal }\end{array}$ & 2001 & 101 & 740 & Oum Rbiaa upstream \\
\hline Touizgui Remz & Assa Zag & 2007 & 18 & 78 & Assa Zag city \\
\hline Al Himer & Settat & 2008 & 38.5 & 14 & Berrechid plain \\
\hline $\begin{array}{l}\text { Koudiat El } \\
\text { Garn }\end{array}$ & Settat & 2012 & 54.5 & 33 & Berrechid plain \\
\hline
\end{tabular}

Source DGE (2015) 


\section{Case study of Wahda dam for El Gharb floodplain control}

Located in the northwest of Morocco, El Gharb plain is the largest irrigated agricultural area of the country with an estimated 250,000 ha of potential irrigated land and a total surface of 616,000 ha. It lays from the Pre-Rif hills and the middle Atlas in the north east to Atlantic Ocean in the west passing by the Mamora forest plateau (Fig. 2.16a). With elevations ranging between 0 and $200 \mathrm{~m}$, it is made up of a coastal zone, continental boundaries, and the central alluvial plain of Sebou. Waterways system is made of wadi Sebou and its main tributaries (Beht, Ouergha, etc.) with an annual contribution of 6 Billion $\mathrm{m}^{3}$, representing $27 \%$ of the national potential of water resources. Mean annual rainfall is $600 \mathrm{~mm}$ in the coastal part decreasing to $470 \mathrm{~mm}$ toward Sidi Kacem in the east (PNE 2015). Climate is Mediterranean type with humid winters and very hot summers. Groundwater resources are estimated at 900 million $\mathrm{m}^{3}$. Population is about 1.9 Million inhabitants (HCP 2014) with 56\% living in rural areas.

This area has experienced several floods. The most devastating ones occurred in the years 1963, 1973, 1989, 1996, 2009, and 2010 generating flooding of several thousand hectares of agricultural land (Fig. 2.16b), damaging infrastructures, destroying houses, and evacuating several affected families. Table 2.7 gives description of El Gharb plain floods most critical recorded damages.

Previous studies, carried out as part of El Gharb plain flood protection, selected the option of constructing Al Wahda dam in 1997 on the Ouergha wadi. The dam has a capacity dedicated for floodwaters storage and evacuation capacity enhancement of the lower Sebou wadi. The dam is the largest one in Morocco with a total capacity of $3800 \mathrm{Mm}^{3}$, a total height of $88 \mathrm{~m}$ and a silting volume of $58 \mathrm{Mm}^{3}$. It is the second-largest dam in Africa after the High Aswan dam in Egypt (UNEP 2008; Arthurton et al. 2008). Al Wahda dam has a positive impact downstream by supplying water for drinking and irrigation and providing 400 Million KW/year of hydropower. Since the dam's completion, flooding has dropped by about $90 \%$. As such, its impoundment came at the right time since it made it possible to laminate the floods of December 1996 and January 1997 and thus avoid damage to infrastructure downstream and crop production.

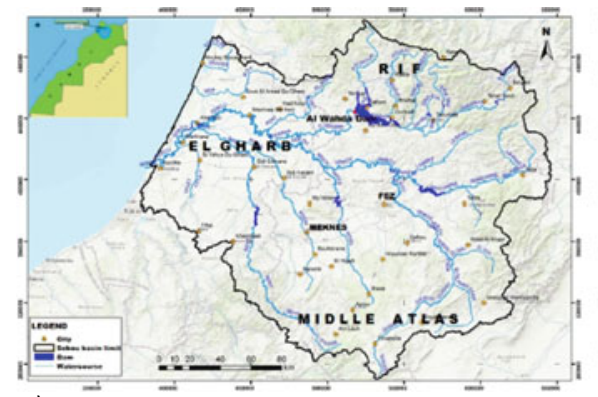

a)

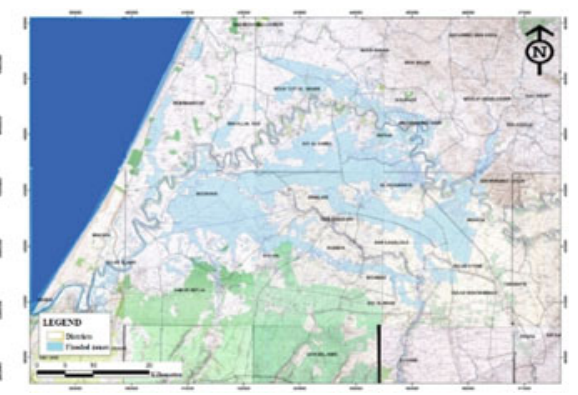

b)

Fig. 2.16 El Gharb plain: a location (Source ABHS 2018); b 2009 flood extent (Source PNE 2015) 
Table 2.7 Historical flood damages in El Gharb Plain, Morocco

\begin{tabular}{|c|c|c|}
\hline Year & Wadis & Damages \\
\hline $\begin{array}{l}1963, \\
1973, \\
1989 \\
\end{array}$ & Sebou & 150,000 ha flooded land, roads, and railways cuts \\
\hline 1996 & $\begin{array}{l}\text { Sebou, Beht, Rdom et } \\
\text { Tifelt }\end{array}$ & $\begin{array}{l}\text { Isolation of cooperative El Kheir, } 1.200 \text { inhabitants } \\
\text { were displaced, } 120,000 \text { ha flooded land }\end{array}$ \\
\hline 2009 & $\begin{array}{l}\text { Sebou, Beht, Rdom, } \\
\text { Tiflet, Smento, } \\
\text { Bouchahla }\end{array}$ & 90,000 ha land and transport infrastructures flooded \\
\hline 2010 & $\begin{array}{l}\text { Sebou, Beht, Rdom, } \\
\text { Tiflet, Smento, } \\
\text { Bouchahla }\end{array}$ & $\begin{array}{l}110,000 \text { ha land and transport infrastructures } \\
\text { flooded }\end{array}$ \\
\hline
\end{tabular}

Source PNE (2015)

It has to be noted that despite storing water upstream the Ouergha basin in El Wahda dam, flood risk remained considerable in the plain. Indeed, El Gharb plain had experienced successive flood events in 2009 and 2010 incurring damages estimated at USD 800 Million. A hydraulic model developed by Midaoui et al. (2015) simulated water flow profiles downstream of Wahda dam for flood events of December 19, 2009 to January 15, 2010 with three successive peak flows ranging from 4000 to $6030 \mathrm{~m}^{3} / \mathrm{s}$. The model showed that the dam preparatory management for rainy seasons helped to avoid a flood on December 21, 2009 and another one on January 07,2010 . The dam yet failed to stop flooding on January 14, 2010 as the dam storage had already reached a fill rate of $104 \%$, but the flood extent was significantly mitigated reducing peak flows.

As many large dams in the world, the risk of erosion of Wahda dam had to be controlled. The initial scheme for Ouergha wadi basin water planning, established by the High Water Council in 1988, defined in addition to Wahda dam, 15 medium-sized dams, and 300 small-sized dams and reservoirs to protect the dams from silting. Examples of these protecting dams are Jorf El Ghorab (1991), Essaf dam (1991), Sahla dam (1994), Bouhouda dam (1998), Asfalou (2000). However, in semi-arid region, environmental impacts of dams are particularly emphasized because of the irregular nature of climate and the intensity of erosive forces. Anthropic actions and drought are the main factors in increasing erosion. Many zones vulnerable to erosion were identified. The steep marly slopes of Rif mountains upstream cause erosion of the Ouergha watershed estimated at $98 \mathrm{t} / \mathrm{ha} /$ year over an area of $6150 \mathrm{~km}^{2}$. Hence, the dam loses an annual volume of $0.6 \mathrm{Mm}^{3}$ (Albergel 2008). Moreover, according to the HCP (2014), there is an important erosion risk in the watershed of Wahda dam that is drained by Ouergha river. In order to improve knowledge of hydro-geomorphological processes Jaouda et al. (2020) mapped the evolution of soil erosion for the period 1990-2014 using Landsat and radar images. They showed that erosion process is still predominant due to important changes in land use, stating the need for soil conservation measures. 
In fact, Wahda dam services are highly important at national level, beside its flood control regional service. It has indeed a strategic role in food-energy-water nexus security, thus solutions to improve Wahda dam longevity and mitigate its reservoir sedimentation have to be found. This was clearly stated in the ABHS revision of its PDAIRE that claimed integrated sustainable solutions to protect the plain from floods based on integrated dam reservoir management as a non-structural measure and development of models for hydrometeorological projections (ABHS 2017). Being directly concerned with flooding of this important agricultural area, the Regional Agricultural Development Office of El Gharb, called ORMVAG, implemented an ambitious program for mitigating flood risk. Indeed, during the period 2009-2013, ORMVAG led cleaning up and dredging operations of all stormwater networks in El Gharb plain, i.e. $4500 \mathrm{~km}$ of channels, in order to cope with the rapid siltation of these networks and to preserve its functionality in mitigating floods (Fig. 2.17).

In 2018, a master plan for flood control and management of Sebou catchment was developed within bilateral cooperation between Morocco and South Corea. The main measures and actions outlined in this plan relate essentially to improving dams' reservoirs operation system, implementing flood prevention and warning system, setting standards, and enforcing legal framework of wadis maintenance system.

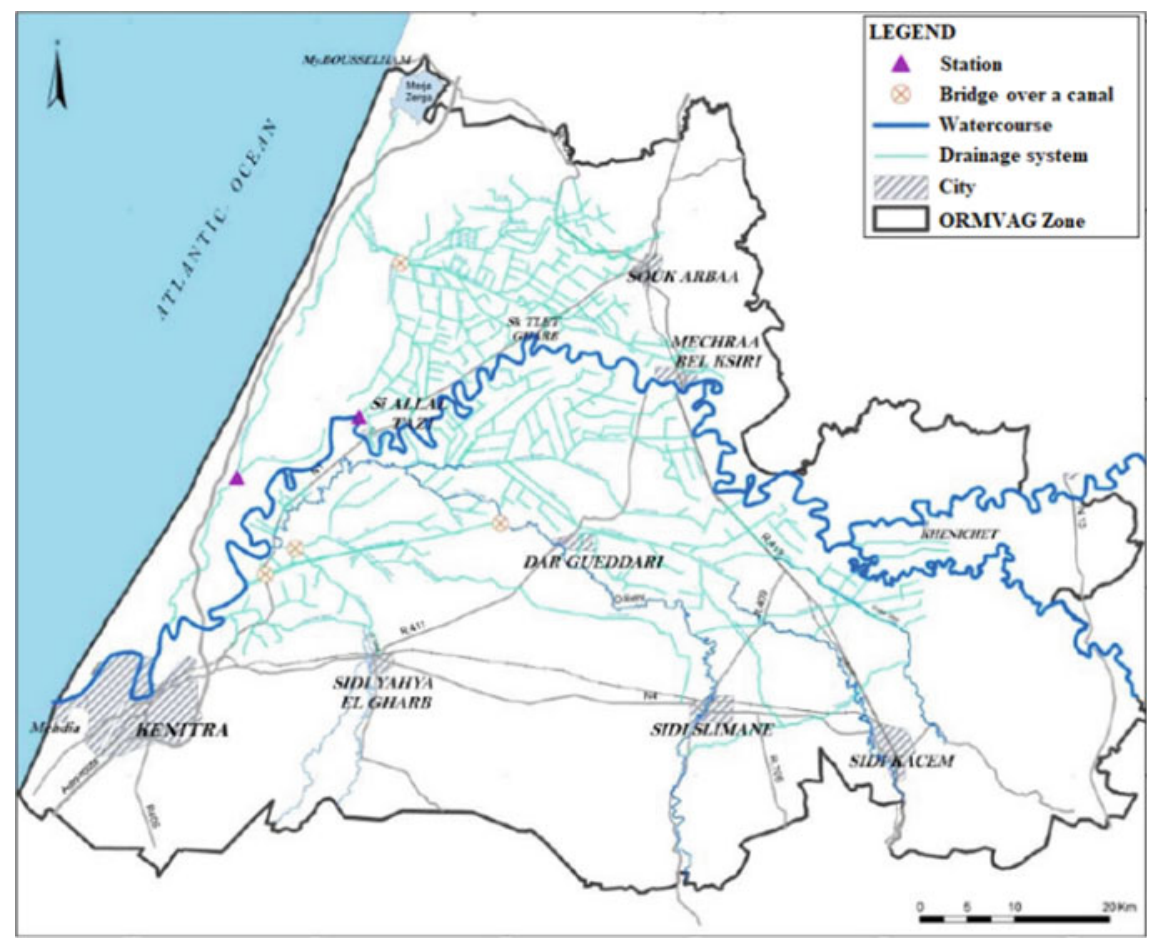

Fig. 2.17 Stormwater drainage system map in El Gharb plain (Source ORMVAG 2017) 
Wahda dam solution was certainly a great response for flood mitigation in El Gharb plain and development of its agriculture potential for national food security. However, erosion risk had deceased its efficiency, particularly in mitigating flood. This measure has been accompanied by other structural measures and non-structural measures including stormwater systems maintenance, and the plan for the dam reservoir and watercourses maintenance. It has to be highlighted though that a cost-benefit analysis has to be made to update the multilevel usefulness of the dam in order to appraise flood prevention and control options. Exploring new techniques for erosion control, storage capacity enhancement, watercourses recalibration, and flood warning systems are some of the options that could be explored for an optimal flood protection that are economically affordable for public budget.

\subsubsection{Other Structural Measures}

As stated in this section introduction, $79 \%$ of the total investment cost for flood control are assigned to structural measures (PNI 2002). In addition to dams, many other structural measures have proved their efficiency in Moroccan practices for flood control. They include embankment protection, spurs and weirs river impoundment, installing culverts, bridges, riffles and fords, demolition operations, and earthworks. An example of a structural measure other than dam, for flood control is the case of the diversion channel Bousekoura Wadi, commonly called SCO.

\section{Case study of SCO diversion channel of Bouskoura wadi Casablanca city flood control}

The economic capital of Morocco, Casablanca, is located on the Atlantic coast about $80 \mathrm{~km}$ south of the administrative capital Rabat. It is characterized by a semi-arid climate with average temperatures ranging from normal to $12.5^{\circ} \mathrm{C}$ in winter to $22{ }^{\circ} \mathrm{C}$ in summer. Annual rainfall totals are characterized by high variability and have an annual mean of $427 \mathrm{~mm}$. They can reach values lower than $200 \mathrm{~mm}$ or sometimes exceed $800 \mathrm{~mm}$. Increasing number and intensity of extreme rainfall events and rapid urban development have affected the performance of urban drainage systems in this city and its suburbs. Indeed, Casablanca has experienced torrential rains on November 27th, 2010 that reached $195 \mathrm{~mm}$ in $24 \mathrm{~h}$, which represents nearly $50 \%$ of the precipitation annual average that was totally recorded in only one day. These precipitations have exceeded the network discharge capacity and gave rise to floods that caused significant damage in this strategic city paralyzing many parts of its territory, especially industrial areas and transport infrastructures. However, the low capacity of the stormwater pipes was not the main cause of this dramatic situation. The city was mostly affected by the overflowing of wadi Bouskoura that reached also many basic infrastructures that cross the wadi and riparian areas during the day of November 30th, 2010 (Fig. 2.18). The wadi crosses the city from the East side to the West side, before flowing into Atlantic Ocean 
a)

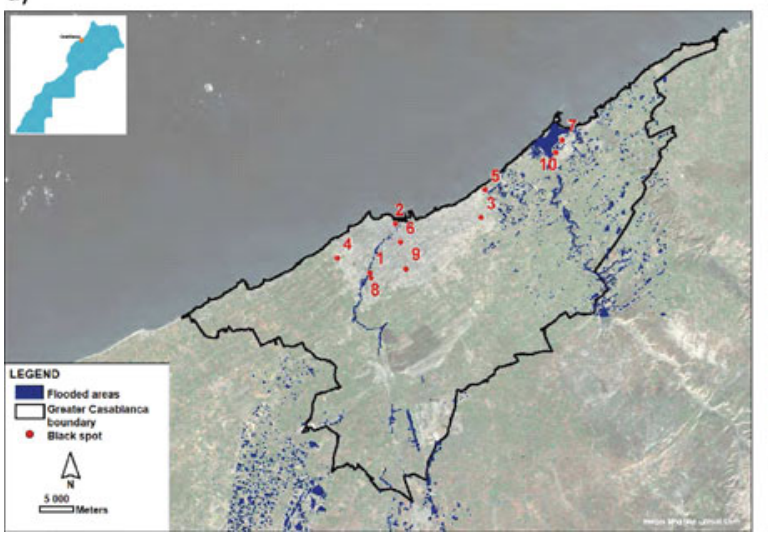

b)

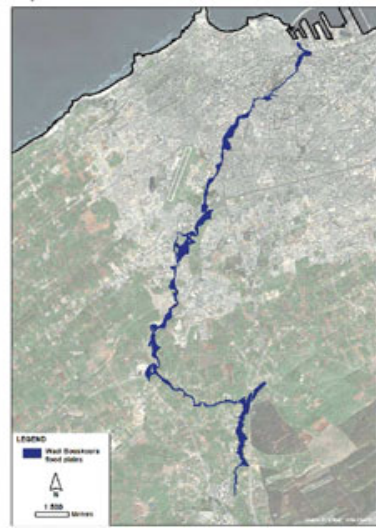

Fig. 2.18 2010 flooded areas in Greater Casablanca a 10 black spots causing most frequent floods; b map of Bouskoura wadi floodplain (Source WB 2011a)

through the stormwater drainage network of the city. In the last two decades, Casablanca has experienced such a rapid economic development in real estate causing the closing off the wadi flow path. Thus, Bouskoura wadi flow cross section at the entrance of the urban area was significantly reduced as the drainage pipe capacity was $2 \mathrm{~m}^{3} / \mathrm{s}$ while the 10 -year return period discharge was $45 \mathrm{~m}^{3} / \mathrm{s}$.

The World Bank study in 2011 showed that for the period 2010-2030, the net present value of potential economic losses due to natural disaster and the impact of climate change for Casablanca are estimated at 1.39 billion dollars, which most would be associated with flooding (WB 2011c). These losses represent $7 \%$ of current gross domestic product (GDP) of Greater Casablanca.

In order to combat the major black spots of overflow in Casablanca, a channelization system, commonly called SCO, has been suggested within the Sewerage Master Plan of Casablanca by the water utility in charge of water supply, sewage systems, and energy in Casablanca, namely LYDEC, a branch of Suez. The suggested measure is a mega-drainage system, called the Super Collecteur Ouest (SCO) combining a $3 \mathrm{~km}$-open channel, for Bouskoura wadi diversion, and a $7 \mathrm{~km}$ underground tunnel with $4 \mathrm{~m}$ diameter discharging at $65 \mathrm{~m}^{3} / \mathrm{s}$ in the Atlantic coast (Fig. 2.19).

The cost of the project implementation was estimated to USD 90 Million which was a heavy investment for the sole public resources. In fact, its implementation was a good example of public-private partnership for flood control measures financing and cost-sharing. The various stakeholders involved in this project funding are shown in Table 2.8.

In November 2018, the SCO proved its efficiency by discharging $30 \mathrm{~m}^{3} / \mathrm{s}$ and making western parts of Casablanca floods free. In addition to the protection in the city of Casablanca against floods, this structural measure enables the city managers to protect basic urban infrastructures; to open important spaces to urbanization; to 


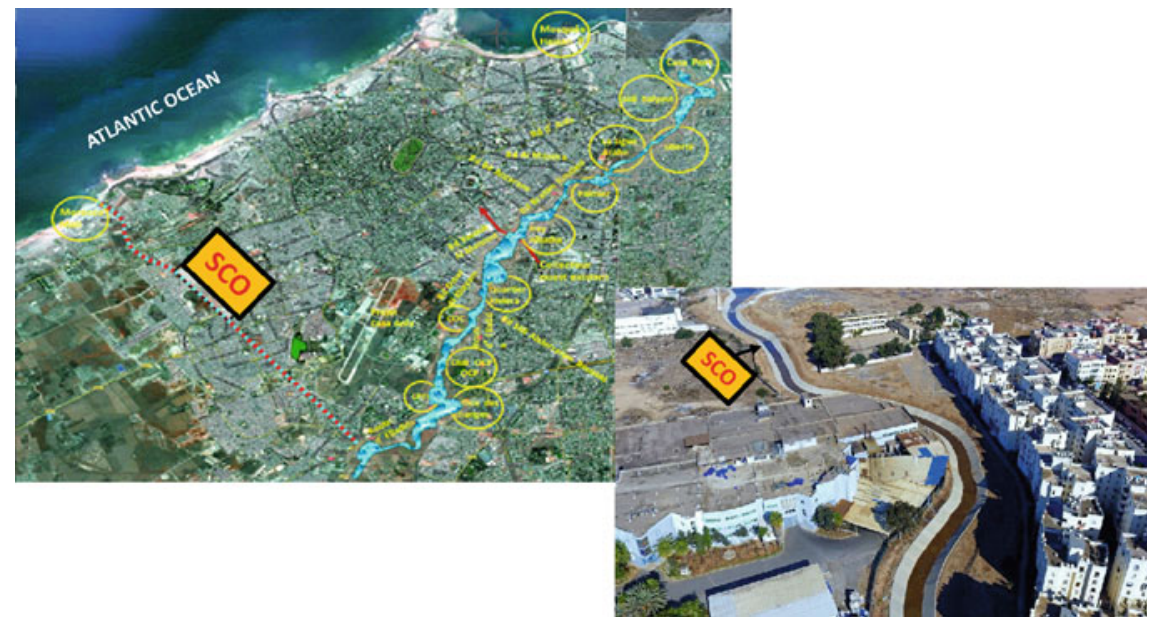

Fig. 2.19 Wadi Bouskoura channelization with the SCO drainage system for Casablanca flood control (Source LYDEC 2014; Casa Aménagement 2020)

Table 2.8 Main Public-Private funding parties of the SCO drainage system for Casablanca flood control

\begin{tabular}{l|l}
\hline Public-private parties & $\begin{array}{l}\text { Financing contribution over 3 years } \\
(2015-2017) \text { in USD Million }\end{array}$ \\
\hline State general budget starting in 2014 & 13.2 \\
\hline $\begin{array}{l}\text { Ministry of interior (fund to combat effects of } \\
\text { natural disasters-FLCN) }\end{array}$ & 13.2 \\
\hline $\begin{array}{l}\text { Ministère of interior (territorial collectivities } \\
\text { directorate) }\end{array}$ & 16.4 \\
\hline $\begin{array}{l}\text { Water department at the ministry of energy, } \\
\text { mines, water, and environment }\end{array}$ & 8.2 \\
\hline Casablanca municipality & 15 \\
\hline Greater Casablanca region & 10 \\
\hline Cherifian office for phosphates (OCP Group) & 8 \\
\hline $\begin{array}{l}\text { Anfa urbanization and development agency } \\
\text { (AUDA) }\end{array}$ & 5 \\
\hline $\begin{array}{l}\text { Hydraulic basin agency of Bouregreg-Chaouia } \\
\text { (ABHBC) }\end{array}$ & 1 \\
\hline Total & $\mathbf{9 0}$ \\
\hline
\end{tabular}

Source Casa Aménagement (2020)

*1 USD is equivalent to about 10 MAD 
protect existing and planned industrial zones; to relocate rainwater outlets in the western part of Casablanca and to resize Bouskoura wadi outlet.

\subsubsection{Flood Warning Systems for Flood Prevention}

The PNI (2002) has planned many non-structural measures as a backup for engineering structural solutions. Investment planning had given a small share to these types of measures showing the weak importance given to them. Yet, the occurrence of flood events in areas that were seemingly protected by structural measures such as dams and watercourse recalibration, had drawn attention of flood management stakeholders to the potential of non-structural measures in improving flood prevention and thus resilience of flood-prone areas. Examples of these measures are flood warning systems, rainwater harvesting, legal framework enforcement, etc. In this way, the adoption of the new water law 36-15 was a good example of a legal non-structural measure as it has brought many adjustments and details for a better-integrated water management including floods and drought control (see Sect. 2.3.2). This law had particularly emphasized on flood warning development all over the Moroccan territory. In the same way, many international cooperation projects recommended the enhancement of warning systems. A typical best practice of non-structural measure for flood prevention is the Ourika flood warning system case.

\section{Case study of Ourika valley and flood warning system in the High Atlas Mountains}

Ourika watershed is a small sub-basin in the high Atlas Mountains, part of Tensift catchment, South of Morocco. It has a surface of $503 \mathrm{~km}^{2}$ at Aghbalou gauging station located about $40 \mathrm{~km}$ to the Southeast of Marrakech city. It is bordered on the east by the watershed of Zat, and on the west by the Rheraya basin, the plain of Haouz at north, and the High Atlas Mountains to the south (Fig. 2.20). The Ourika basin is characterized by high elevation and steep slopes upstream of the wadi. $75 \%$ of the basin is located between $1600 \mathrm{~m}$ and $4165 \mathrm{~m}$ elevations and slopes can reach $60^{\circ}$ to $70^{\circ}$. When intense rains occur, these slopes along with the land surface high imperviousness increase runoff generating the rise of floods (Bennani et al. 2019). The rainy period is October-April and the dry period is May-September with an average annual rainfall at the High Atlas ranging from $600 \mathrm{~mm}$ to $800 \mathrm{~mm}$. The hydrological context of the Ourika watershed is influenced by a very marked seasonal and inter-annual irregularity of precipitation and heterogeneity of their spatial distribution (Saidi et al. 2003; Zkhiri et al. 2017). The drainage network is causing serious flooding by the extension of water bodies during periods of heavy rainfall, between July and October generating important damages for populations and infrastructures. The basin experienced many floods in 1984, 1987, 19951999 , and 2014 that pushed water authorities to seek solutions for flood control. The case of the 17 of August 1995 was particularly severe as more than 200 people lost their 
Fig. 2.20 Geographic location of Ourika watershed, Morocco (Modified from Bennani et al. 2019)

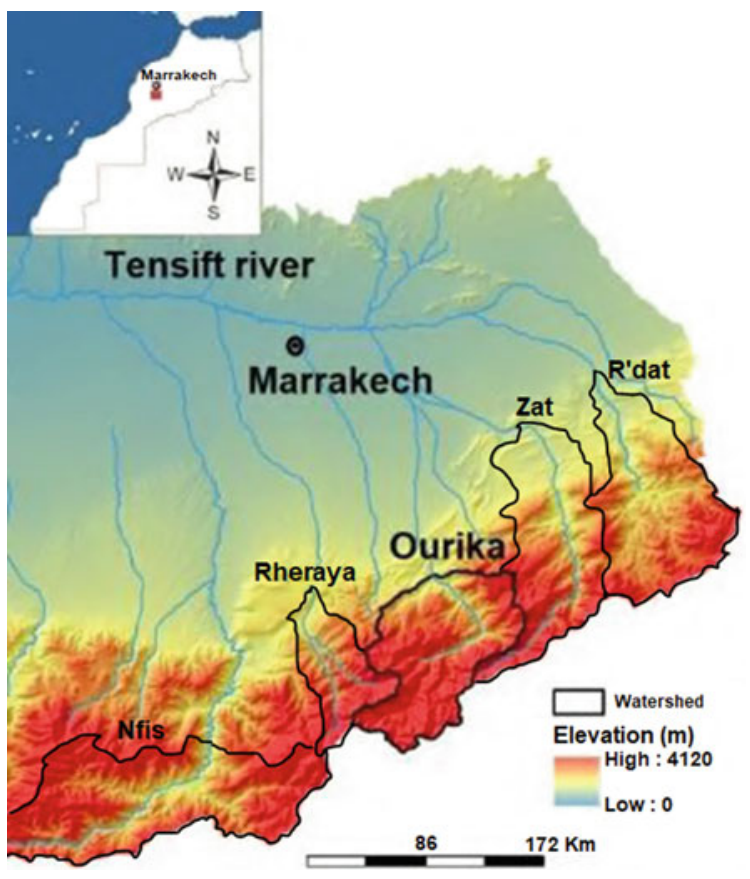

lives, many persons were missing, 300 ha of agricultural land were inundated, among which 62 ha were lost, and enormous material damage occurred (Daoudi and Saidi 2008). Besides, this mountainous basin is a touristic area that is massively visited during summer, and many touristic infrastructures, such as hotels and restaurants located nearby the river bed, were affected. The rainfall intensity was about $100 \mathrm{~mm} / \mathrm{h}$ upstream the Ourika basin having generated a peak flow of $1000 \mathrm{~m}^{3} / \mathrm{s}$ within $15 \mathrm{mn}$. Sediments accumulation has played a major role in aggravating the damages as it initially blocked the runoff by forming a natural dam that has later on collapsed creating a sharp hydrograph downstream and bringing alluvial cones into the wadi. In October 1999, another flood hit the Ourika valley and its neighboring watersheds including R'dat, Zat, Rheraya, and N'fiss. The rainfall and peak discharge reached $103.8 \mathrm{~mm} /$ day and $762 \mathrm{~m}^{3} / \mathrm{s}$, respectively. No human causalities were recorded but infrastructure and agricultural areas were damaged.

After the 1995 disaster, structural measures against flood have been implemented in the Ourika basin given its importance in terms of touristic activities and flood exposure. Ministry of Equipment (ME) has mainly concentrated on the Ourika water streams to mitigate occurrence of debris flow as well as to enlarge floodwater carrying capacity. Such measures included riverbed excavation along $12 \mathrm{~km}$ to ensure discharge capacity for floodwater, riverbank formation and protection with large gravel and revetment works to protect damaged road linking Marrakech city to Ourika valley. In addition, 27 small check dams were constructed 
by the ME in the Ourika basin as of April 2000 to prevent outbreak of debris flow in the eight tributaries of Ourika wadi. Other small dams were built in the main wadi course to reduce the flow speeds and bank erosion as well as sediment transport. However, upstream of check dams were still causing important raise of water level increasing flood risk. In order to complement this set of structural measures and improve flood mitigation efficiency, other non-structural measures were added. Indeed, the High Commissioner for Water, Forests, and the Fight against Desertification (HCEFLCD) implemented a master plan of reforestation in order to mitigate erosion risk. A reforestation of two watersheds of Ourika and R'dat was carried out with a total treated surfaces of 2093 ha in Ourika basin and 3389 ha in the R'dat basin during the period 2000-2006.

All these measures were tightly reliant upon a good knowledge of hydro-meteorological conditions. Besides, the safety of the population required a good warning system in this mountainous and yet highly touristic area. Therefore, in march 2000, Moroccan government sought the support of the Japan International Cooperation Agency (JICA) to conduct a study for implementing a Master Plan for Flood Forecasting and Warning System (FFWS) for Atlas Region (JICA 2004). Thus, in 2001, five new hydrological stations were installed in the Ourika basin and another one in Rheraya basin as they were badly hit by the disaster (Fig. 2.21a). These stations were equipped with a VHF/FM and/or a HF/SSB radiotelephone to report flood information to the regional water authority. Two data transmission stations, four monitoring posts, and a warning post located at Ighref were also implemented. In addition, for a better integrated regional management of water resources, Tensift Hydraulic Basin Agency ABHT was created in 2000 having the responsibility, among others, of flood management. The ABHT included in its

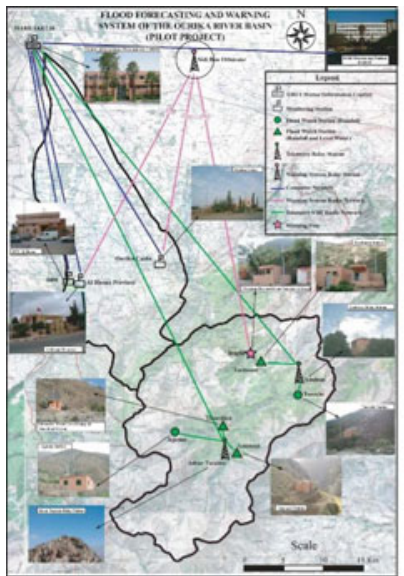

a)

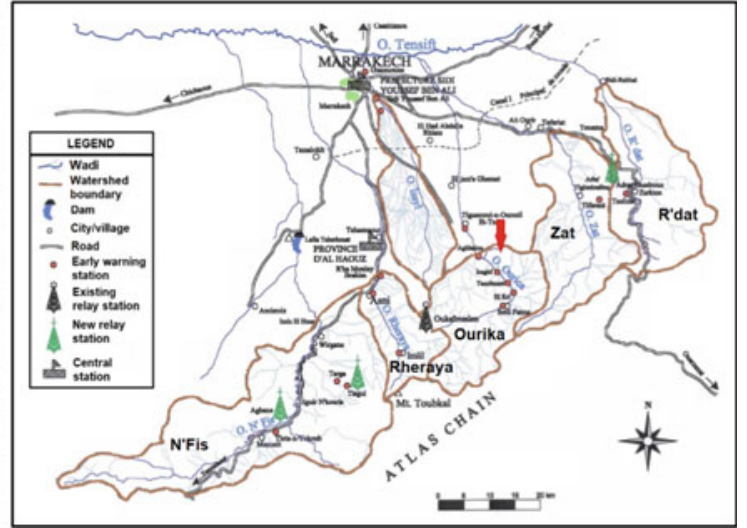

b)

Fig. 2.21 Flood forecasting and warning system (FFWS) for the high Atlas: a FFWS stations in Ourika valley 2004, b FFWS stations in all Tensift High Atlas sub-catchments 2010 (Source JICA 2004) 
PDAIRE the FFWS by extending it to five other watersheds, namely Rdat, Zat, Rheraya, Issyl, and Nfis (Fig. 2.21b). Since 2007, the ABHT has financed the telemetry network extension to 16 sites, including 3 rainfall stations and 13 rainfall-limnometric stations (ABHT 2010). The Ourika valley FFWS played a successful role in the detection and warning of ten floods between 2003 and 2012. During the 2014 floods, which affected Al Haouz province, no loss of life was recorded despite some property damages. In addition to providing an efficient early warning system, this project has raised local populations awareness toward emergency procedures. Currently, when flooding occurs, many local volunteers are tasked with warning tourists, keeping them informed, and helping them evacuate (OECD 2017b).

In its PDAIRE, the ABHT has assessed a total of 88 flood-prone areas over Tensit catchment territory. To tackle this problem, a program for flood risk protection was planned for the period of 2010-2020 and 2021-2030. 15\% of the total budget of this program is dedicated to non-structural measures that are basically consisting of land use regulation in flood zones through delineation studies, awareness raising of the population, and the extension of flood forecast and warning systems. The ABHT has nowadays 42 hydrometeorological stations, 7 control posts, 7 transmission relays and 18 alarm posts. $98 \%$ of hydrological stations are equipped with telemetry. Data transmission is ensured by Radio across all sites. In 2019, the ABHT began to install redundancy networks with LTE wireless broadband (ABHT 2019).

\subsubsection{Other Non-structural Measures}

Most of the PDAIREs have integrated non-structural measures in their financial plans for flood control. In addition to flood warning systems, these measures include watercourses maintenance, watersheds management, contingency plans, information, training, and coordination. These choices were made based on the PNI (2002) recommendations. However, the PNE (2015) recalled that other measures should be contained in action plans for flood control, such as:

- reform of the legislative framework governing the management of flood risk;

- delineation of areas at flood risk and their mapping for each catchment;

- linkage between planning and land use development documents in order to control land use in areas at flood risk;

- flood prevention enhancement by improving knowledge in the field of hydrometeorological forecasting and the development of flood forecasting and warning and emergency plans;

- reinforcement of financial mechanisms (i.e. insurance and funds for natural disasters mitigation), in addition to consultation and coordination.

These new non-structural measures are being integrated into the latest update of the PNI. In the meanwhile, many governmental bodies have already taken actions for 
implementing such measures. Some successful examples of these achievements are the new water 36-15 enactment, the creation of the FLCN fund for mitigating natural disaster impacts, production of new maps of aptitude for urbanization, and recently the creation of the Fund of Solidarity against Catastrophic Events (FSEC).

\section{Legislative measure: Law 36-15}

A good example of legislative measures for flood management is the new law 36-15, enacted in 2016. As introduced in paragraph, this law gives provisions of flood control, prevention, and management in a more detailed way that was absent in the previous water law 10-95. The new water law emphasizes on the management of water-related risks in particular floods and water scarcity. For floods, the law dedicated many articles on protection and prevention of flood risks, detection, monitoring, warning and management of flood events, and the implementation of water information system (Table 2.9). This legislative measure is a very important step in adapting the legal framework and therefore the administrative action to climate change related risks including floods. Similar efforts are still to be continued through the publication of pending implementation instruments of this law related to the novel documents that it provided. This is particularly the case of:

Table 2.9 Comparison of flood provisions between law 10-95 and the new law 36-15

\begin{tabular}{l|l}
\hline Law 10-95 & Law 36-15 \\
\hline $\begin{array}{l}\text { ABH liability for implementing flood } \\
\text { prevention and control measures } \\
\text { art.20) }\end{array}$ & - Flood definition (art.3) \\
\hline $\begin{array}{l}\text { Flood control infrastructures and } \\
\text { prohibited construction areas } \\
\text { (art.94-97) }\end{array}$ & $\begin{array}{l}- \text { ABH liability for identifying and realizing } \\
\text { flood prevention and control measures (art.80) }\end{array}$ \\
\hline & $\begin{array}{l}\text { - Atlas of Flood prone areas based on } \\
\text { three-level risk classification (art.118) }\end{array}$ \\
\hline $\begin{array}{l}- \text { Plans for Flood Risk Prevention to be } \\
\text { prepared by ABH for medium and high flood } \\
\text { risk areas in coordination with related } \\
\text { stakeholders (art.118) }\end{array}$ \\
$\begin{array}{l}- \text { Integrated Flood Monitoring and Warning } \\
\text { Systems to be implemented in all flooding } \\
\text { streams (art.121-122) }\end{array}$ \\
$\begin{array}{l}- \text { Communication between General Directorate } \\
\text { of Meteorology and ABH for providing } \\
\text { necessary metrological forecast to the } \\
\text { Integrated monitoring and warning systems } \\
\text { (art.121) }\end{array}$ \\
$\begin{array}{l}- \text { Vigilance committees' creation at national and } \\
\text { regional levels for flood events management } \\
\text { (art.123) }\end{array}$ \\
\hline
\end{tabular}


- The procedures for establishing and approving Flood Risk Prevention Plans. These plans are made for a period of 20 years.

- The conditions and procedures for establishing and operating Integrated Flood Monitoring and Warning Systems to be implemented in all flooding streams.

- The composition and operating procedures of the new Vigilance Committees that will be established at national and regional levels for flood events management chaired by the governmental authority in charge of the Interior.

\section{Financial measure: The FLCN fund}

Another successful measure is the implementation of the Fund to combat the effect of Natural Disasters, called FLCN. The fund was created in 2009, with the support of the WB and the assistance of the OECD, and put under the auspices of the MI. Initially, the fund was mainly dedicated to cover emergency response and post-disaster reconstruction; it has gradually evolved into prevention financing. Thus, the fund has launched call for projects every year since 2015 in order to support projects of public stakeholders involved in risk management, namely the ministerial departments, public institutions, and companies, or territorial community elected councils. During the 2015-2018 period, the fund hence co-financed a total of 97 projects, through these calls, supporting both structural and non-structural measures for disaster prevention. In 2019, call submission, 75 applications were received, most of them from territorial community councils, and 46 projects were related to structural measures and 29 for non-structural measures.

For flood disaster prevention, the fund is supporting structural measures such as infrastructures for flood control or elevation of public infrastructures exposed to flood (e.g. public buildings, bridges, airports, ports), and non-structural measures such as plans for flood risk mitigation, warning systems, resilience regulations improvement and structures to monitor their application in urban and land use planning, floor risk mapping. For flood disaster prevention, the fund is supporting structural measures such as infrastructures for flood control or elevation of public infrastructures exposed to flood (e.g. public buildings, bridges, airports, ports), and non-structural measures such as plans for flood risk mitigation, warning systems, flood risk mapping, resilience regulations improvement and structures to monitor their application in urban and land use planning.

Most of the disaster control projects supported so far by the FLCN are related to flood control and related measures led by ABHs for studying and implementing flood protection measures in flood-prone areas, or installation of new radars for data monitoring and automation of meteorological stations investigated by DGM, or urbanization aptitude mapping undertaken by the Ministry of Urban Planning or Urban Agencies. Examples of such projects funded by the FLCN are:

- Modernization of meteorological services within the framework of the VIGIOBS project (Issara et al. 2010). The number of automatic weather stations has thus increased from 50 to more than 200, and the number of radars from 6 to 8. The FLCN has mobilized funding of USD 13.5 million over the period 20102012 for this project. 
- The SCO diverting channel of Bouskoura wadi. This project has reduced floods of the city of Casablanca and Bouskoura. The FLCN mobilized 14\% of the total budget for this project for the period 2015-2017.

The FLCN measure has enabled Moroccan state to have a specific financial tool for risk management. This fund will leverage other sources of funding as the FLCN contributes up to $50-70 \%$ of the total cost of eligible projects (MI 2020).

\section{Urban planning measure: Urbanization Aptitude Map}

Al Hoceima, a city in north Morocco on the Mediterranean shores, has experience successive natural disasters that are floods in 2003, the devastating earthquake of 2004 , and landslides in 2008. As a response, the MI launched with the support of the WB a program on Integrated Disaster risk management and Resilience to assess Morocco's exposure to natural risk hazards and suggest recommendations for mitigating these risks. Following these program recommendations, the first urbanization aptitude map, called CAU, was elaborated in 2012 for Al Hoceima city. It is a major decision-making tool for earthquake-Flood and landslide risks management as it represents a real basis for the preparation and updating of urban planning documents and the regulation of land use and planning for this city. In 2017, $62 \%$ of urban planning documents of $\mathrm{Al}$ Hoceima city have incorporated the provisions of the CAU (Al Hoceima Urban Agency, AUA 2017). Following the implementation of the FLCN financial tool and the launch of its calls for proposals in 2015, a governmental program for elaborating 31 CAUs through the Moroccan territory was established for the period 2016-2021, thus many urban agencies received this fund support to elaborate their maps.

Regarding the risk of flooding, urbanization aptitude maps are based on the exploitation of Flood Atlas maps elaborated by the $\mathrm{ABH}$ and more detailed studies on most vulnerable sites. Therefore, these maps involve the implementation of the classification and mapping of flood risk based on field investigations concerning the areas at stake; analysis of hydro-meteorological data; a hydro-geomorphological study, and hydraulic modeling of urbanized areas. Different types of hazard maps, including flood maps, are then crossed and synthesized under a single cartographic document that is the CAU. This map defines five urban area classes:

- Constructible areas: Areas deemed to have no significant natural risk;

- Constructible areas under technical conditions: Low-risk areas, which can be built under conditions for carrying out general improvements;

- Constructible areas under special conditions: Medium-risk areas, which can be built under specific measures to be taken by urban and real estate developers;

- Non-constructible areas: Areas at high risk.

- Non aedificandi areas: presenting risks of flood, landslide, or earthquake which cannot be rectified.

Figure 2.22 shows an example of an urbanization aptitude map of Taounate city, northern Morocco (AUT 2017). The ongoing generalization of these maps to the whole Moroccan territory is a good example of compelling administrative planning tools as a non-structural measure for flood risk management. 
Fig. 2.22 Taounate city urbanization aptitude map (Source AUT 2017)

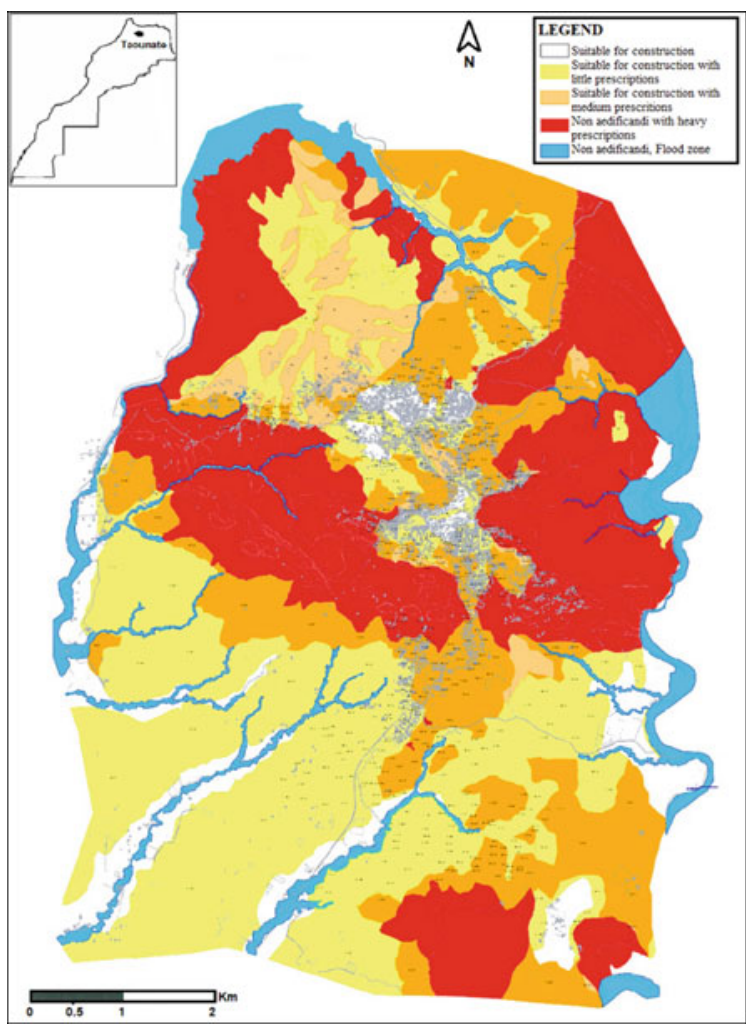

\subsection{Swot Analysis and Recommendations}

In this work, many research articles, administration documents, consultancy, and international organizations reports were analyzed to give a holistic insight on flood risk management in Morocco and form a critical view from a scientific perspective. Information and data were collected from different sources to come up with one document that integrates all scientific and governance aspects of flood risk management in Morocco. Analysis of this management landscape shows the important advances made by the Government to protect the population and prevent flood risk, but also the shortcomings that were or are still to be overcome. Given the variety of these aspects, a SWOT analysis (Hill and Westbrook 1997) was carried out for scoping and identifying the strengths, weaknesses, opportunities, and threats related to flood risk management in Morocco. Results are shown in Fig. 2.23. The analysis revealed various flood risk management success and failure factors related to three major components that are: governance, risk assessment approaches, and flood risk mitigation measures sustainability. 


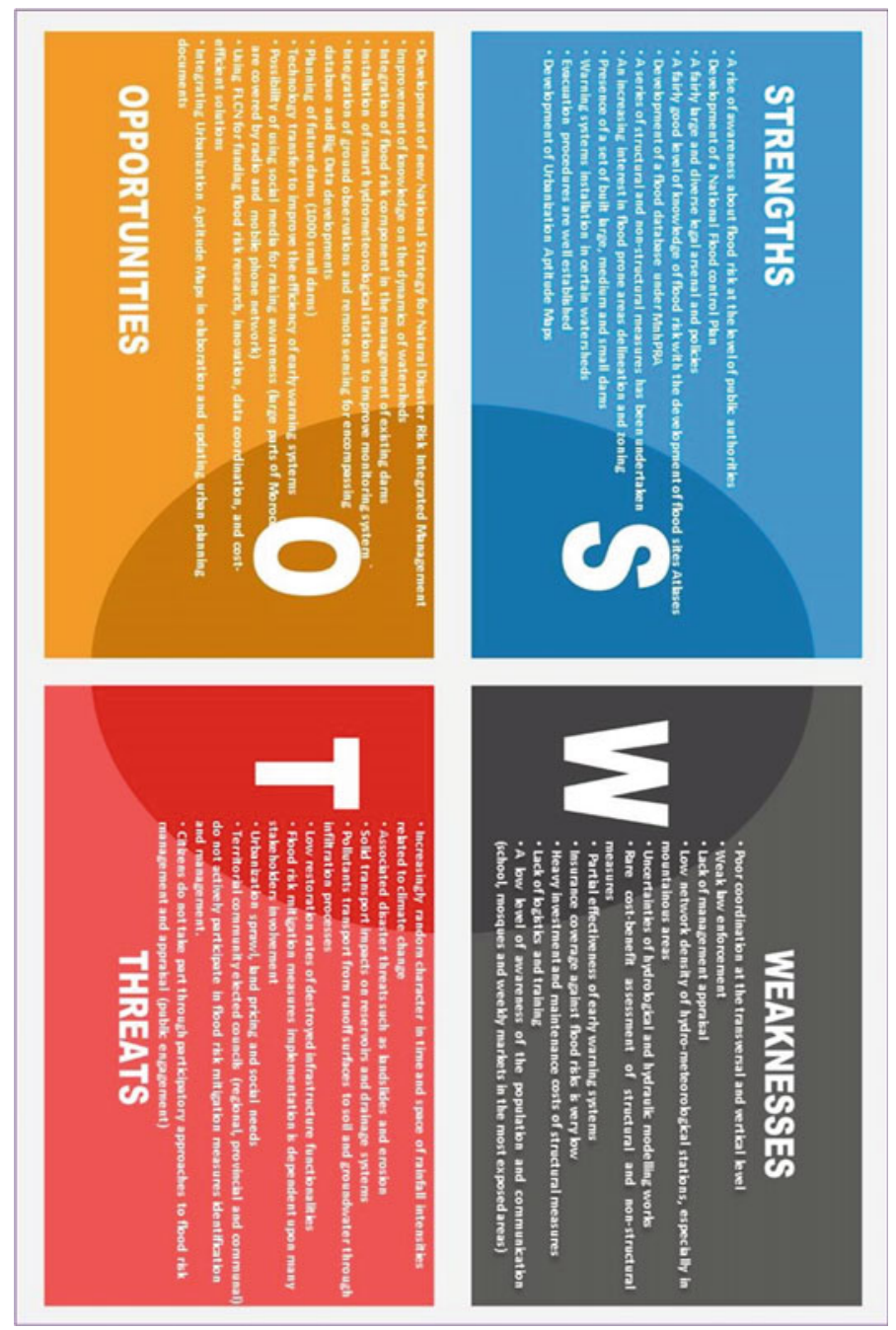

Fig. 2.23 SWOT analysis of flood risk management in Morocco 2020

Governance issues: In general, Morocco has made considerable progress in managing the risk of one of the most costly and adverse disasters for the past fifty years that is flood. The existence of legal arsenal, flood dedicated national plan (PNI), and integration of flood prevention and control in regional water agencies plans are all premises of a real awareness of public authorities and an advantageous framework for flood risk management. The paradigm shift from reactive to proactive approach in flood risk management, thrusted by international organizations, is also another positive advance in the process of risk management. However, the multiplicity of stakeholders, the poor coordination at transversal and vertical 
levels, the weak law enforcement, particularly in the delineation and use of flood-prone areas are still impediments to the improvement of this management. The appraisal process is not implemented yet as a common practice for updating and adapting the development of flood risk management strategies. The prevention approach is still being developed but in an unequal manner between the ten $\mathrm{ABHs}$ (flood atlases, PDAIRE updates) despite the provisions of the newly elaborated water law. Indeed, on legislative level, the water law 36-15 has undoubtedly the merit of introducing for the first-time provisions dedicated to flood management. However, many of its implementation instruments are still pending generating discrepancies in flood prevention actions implementation.

The ongoing development of a risk management national strategy is a good opportunity to come up with solutions for these discrepancies and deficiencies. The MI leading this strategy is indeed the right department that can coordinates effectively flood prevention and control as it does for flood emergency and crisis management. The recent trainings, communication efforts, and the positive responses of stakeholders are good indicators of the potential of this leadership. Moreover, the financial hurdles that most of the implementation parties were facing in terms of heavy investment and/or maintenance costs of structural and non-structural measures, were largely reduced by the creation of the FLCN under the MI management. The call for proposals launched each year by the FLCN receives indeed increasing numbers of proposals from a variety of eligible public institutions and consolidates the role of this ministry in the coordination challenge.

The newly created Provincial Coordination Centers in the four locations, cited in Sect. 2.3.2, are also expected to improve local coordination between the multiple stakeholders and advocate for the creation of new directives for better legal responsibilities description and differentiation.

Among the 96 projects financed by the FLCN through calls for proposals over the period 2015-2018, only one project was investigated by a consortium of three research institutions. The project was on natural risk study in the central Rif. A special interest should be given to research institutions to encourage more interaction between the different stakeholders for advancing research on natural risk assessment. Indeed, flood risk is a particularly transversal issue involving many administrations and data providers. The FLCN can be a good framework for promoting collaboration between different partners.

Flood Atlas maps and their updates by $\mathrm{ABHs}$ are an essential prerequisite for urbanization aptitude maps (CAU) elaboration by urban agencies. The absence or lack of accuracy of such maps may affect the development of such map, essential to harness the rapid development of land use and urbanization sprawl. Therefore, the process of updating such maps should be adapted to urban planning requirements. The fact that many projects financed by the FLCN were dedicated to elaborating Urbanization Aptitude Maps proves the urgent need for these documents. However, a close look at the process of establishing such document shows that it goes through a hydrological and hydraulic modeling work for accurate risk assessment. This part should be closely coordinated with ABHs for more technical and accurate risk assessment and to avoid redundancy in flood risk studies. 
Although flood-prone zones atlases have been produced at the scale of each $\mathrm{ABH}$, these documents remain very general and only informative. They were not followed by the implementation of Prevention Plan against Flood Risk (called PPRI), a document that is more concise and should give accurate delimitation of flood zones, heights, and velocity reached at different points in these zones, identification of exposure and risks, and recommendations for suitable measures for future urbanization (DRPE 2013). Accelerating the production of pending implementation instruments of related provisions in law 36-15 will certainly help in the elaboration of these plans.

Technical issues: another strength of Moroccan flood risk management is the development of flood risk modeling since nineties despite the lack of data in terms of time and spatial distribution. Modeling works, mostly carried out by $\mathrm{ABH}$ and the Water Department gave a fairly primary assessment of flood risk at national and catchment scales that formed the basis for establishing PNI, PNE, catchment's flood atlas, and selecting flood control measures and their integration in budget planning. Since the launch of the program for establishing 31 urbanization aptitude maps (CAU) by the land use and urban planning ministry, many urban agencies performed their own flood risk modeling downscaled to their urban action perimeters. However, accuracy of these studies is a real weakness for the following reasons:

- Hazard assessment: no study has made a downscaling to simulate future trends of extreme rainfall events intensities, especially for short durations of few hours, that are often the cause of flash floods. Table 2.1 gives indications on duration of extreme precipitations that caused floods.

- Rainfall-runoff processes are often estimated based on stochastic methods and calibrated with discharge measurements when they exist. Estimates of design floods are often missing to initiate any hydraulic modeling for water infrastructures in the region (Zemzami et al. 2012). IDF curves are often used to estimate future rainfall intensities based on the Talbot-Montana model (Moujahid et al. 2018). However, these curves need to be updated by DGM for each meteorological station as climate change has considerably affected their accuracy.

- In mountainous areas, floods are greatly affected by geomorphological and hydrographic characteristics of watersheds. Steep slope, dense drainage network, compact shape, unvegetated surface, low infiltration soils increase the rainfall-runoff process paving the way to important floods in upstream basins (e.g. Ourika, Upper Moulouya, Rif, etc.). Therefore, catching these characteristics in fine detail is crucial for an accurate hydraulic modeling and flood risk assessment. Indeed, Bennani et al. (2019) analyzed the impact of two digital elevation models (DEM), with $30 \mathrm{~m}$ and $4 \mathrm{~m}$ spatial resolution on the accuracy of hydraulic models of Ourika watershed. They showed that a realistic representation of topography is essential to simulate flood in areas where data are scarce. The development of remote sensing public resources is a good opportunity for hydraulic modeling improvement. However, their resolution is not 
always sufficient to accurately describe the geomorphological characteristics of mountainous watersheds.

- In both versions of the PNI, the primary recommendation was the improvement of flood risk knowledge. An accurate scientific risk assessment requires indeed a good knowledge of hazard and vulnerability. However, it became clear from the technical approaches adopted in PNI and Flood Atlases so far, that data sparsity and short records, and lack of high-resolution topography maps hampered the development of more accurate risk maps. It was obvious that, in 2002, with the pressing need for a more preventive flood policy, accuracy of maps was not a priority. Yet, it is clear that the present development of technology and data resources, including satellite and UAV data and the advent of big data, machine learning, and more broadly artificial intelligence, can develop a better risk assessment knowledge and thus, help decision makers in optimizing investment in flood protection measures. It can also overcome the obstacle of data exchange and communication between various and large arrays of institutional stakeholders.

- Vulnerability assessment needs to be refined in urban areas. The newly developed Urbanization Aptitude Maps are certainly an opportunity to come up with deficiencies in urban vulnerability assessment as it is strongly linked to urban and real estate factors.

- Exposure was not considered in the PNI and PDAIRE first editions as the knowledge about this risk element was not fully acquired. Vulnerability was assimilated as exposure. Besides, exposure data are often collected from various institutions with different levels of availability. In fact, a fair good coverage of social data, urban data, land use is available. However, economical value is still a weak link in the process of exposure assessment.

- MnhPRA is a good GIS-based tool for a first assessment of risk in Morocco. However, this tool is not accessible to researchers so that a scientific and technical improvement of this tool can be performed. In addition, law 36-15 provision about the implementation of a new Integrated Systems for Flood Monitoring and Warning could be a good opportunity for linking this system to MnhPRA to improve its accuracy and usage in partnership with the scientific research community.

- So far, there is no standard in Morocco defining reference or threshold hazards. The 2016 water law 36-15 states that flood risk atlases should define three levels of hazards — low, medium, and high — without fixing the related return period. In Europe, the 100-years return period that has long served as a reference is now considered to be the average level. In the OECD guide for Morocco (OECD 2018), return periods of 10-20 years, 50 years, and 100 years were recommended.

\section{Mitigation measures, sustainability, and resilience issues}

Many measures have proven their efficiency in flood control, such as the SCO channel for protecting Casablanca city and the new El Malleh dam for Mohammedia city. In fact, the set of dams realized within the dam's policy is a 
major asset for Morocco's water resources integrated management strategy including flood protection. In the PDAIREs, the primary implemented flood protection measures were the traditional engineering ones, generally consisting of programs of dams, levees, and channels building. Cost estimation of these measures is usually based upon the method used in the PNI (2002), where investment costs were computed using a classification of sites according to the size of the urban area and flood vulnerability, and the estimation of a cost class ratio based on previous sites studies. However, no cost-benefit analysis has been integrated into the process of selecting mitigation options. Besides, the environmental and social impacts of large dams and structural measures are often neglected. Indeed, these large infrastructures generally require substantial land provisions and real estate acquisition, generating adverse social impact and important threat to flood control measures acceptance. Moreover, erosion is another serious threat to Moroccan dams as their silting puts the sustainability of these structures in jeopardy. Erosion affects also the hydraulic performance of drainage and sewage systems (e.g., El Gharb). Maintenance of these structural measures can be a hurdle to water managers that seriously affects their performance in protecting against floods in the long term.

Large reservoirs have the advantage of economy of scale but they are costly to build and maintain, and they can result in massive social and environmental disturbances. Cost-benefit analyses should be required for flood risk studies done by $\mathrm{ABHs}$ and DGE for a better investment adjustment and sustainable protection.

Lessons from neighboring countries should be drawn. Indeed, Aswan High Dam offered Egyptians a way to control runoff from the Nile and to provide a stable water supply but hard-pressed the country financially and politically to secure funding. The dam successfully stopped damage from seasonal flooding but blocked sediment that floodwater brought with it to replenish the Nile Delta and therefore, increased its vulnerability to erosion (Syvitski 2008; Verner 2012). For flood control channel in Sfax city, Tunisia, water deterioration in the channel is firstly related to contaminated groundwater drained by the channel and secondly to anthropogenic inputs (Dahri et al. 2014). The sustainability of flood measures, particularly structural ones, should be integral part of options selection. For instance, enhancing dam's sustainability can be achieved by prospecting new ways of designing dams. Indeed, studies in Spain and China showed that hybrid connection of check dams' system can generate the largest decrease in flood magnitude better than the parallel system and to a lesser degree, the series of dam system. The construction of check dams is an important instrument in holding sediment from reaching downstream infrastructure and for reducing flood amplitude in a cascading way (Boix-Fayos et al. 2008; Yuan et al. 2019). Leichao 2020 showed that the sediment interception efficiency of check dams can be greatly reduced under extreme rainstorms when these dams are poorly managed. They concluded that management and construction technology standards of check dams for flood and erosion control should be improved to keep up the efficiency of dams' systems.

The need for future dams may be obvious for flood control as extreme rainfall-runoff are varying under climate change. However, the random character of climate change poses also the risk of oversizing these structures and therefore 
reducing their efficiency. Yet, the succession of long sequences of drought in 19801985; 1991-1995; 1998-2002; 2004-2008, asserts the need for dams to alleviate drought impact on water resources, drought events being considered as natural disasters far more damaging economically and socially than floods in Morocco. Therefore, updating national and regional water policies (PNI, PDAIREs) is a good opportunity to reassess the role of existing or new dams, primarily designed for hydropower or irrigation, with the additional purpose of flood mitigation. Hence, cost-benefit analyses should be a necessary step in defining program of dams' construction and should integrate all services provided by large dams including water availability, hydropower generation, and flood control.

Besides, relying on dams alone for long-term protection is a real threat to flood resilience. Indeed, the examples of al Wahda dam built in 1996 that failed in protecting Al Ghrab plain against the 2010 floods, the Assif El Krayma hill dam built in 2012 that failed in protecting Sidi Ifni city in Moroccan desert against 2014 floods, have demonstrated how much it was dangerous to rely solely on these types of measures for flood control. Indeed, non-structural measures are required to accompany structural ones for a better resilience. The Ourika case is a good example of combination of structural and non-structural measure for flood risk management and resilience enhancement. However, a close look at numbers and investment shares in non-structural measures shows their low consideration in regional planning, highlighting a weakness of flood risk management in Morocco. Update of flood risk management plans should be an opportunity to consider the benefit of these measures and increase their shares in investment planning. As these measures often require a public engagement to ensure their long-term efficiency, absence of citizen involvement in decision-making may be a threat to the sustainability of such measures. Nevertheless, the provision of law 36-15 for preparing new Flood Risk Prevention Plan for high and medium risk areas is the right opportunity to stimulate the engagement of citizens and other public stakeholders within a participatory approach for a better communication, flood risk preparedness and resilience enhancement. Lastly, the involvement of international organizations, such as OECD and WB, was a good opportunity for Moroccan government to advance its flood risk management strategy. International cooperation in research can also offer a great opportunity for improving flood risk assessment in Morocco and developing innovative solutions for flood prevention and control.

\section{References}

ABHBC (2007) Etude du Plan Directeur d'Aménagement Intégré des Ressources en Eau du Bassin Hydraulique du Bouregreg et de la Chaouia. Rapport sous Mission I-2: Evaluation quantitative des ressources en en eau et des écosystèmes. Hydraulic Basin Agency of Bouregreg and Chaouia report

ABHS (2017) Gestion du risque d'inondation dans le bassin du Sebou. Hydraulic Basin Agency of Sebou communication. In: OECD workshop on risk prevention in Morocco, Fez, Morocco 
ABHS (2018) Surface water resources. Hydraulic Basin Agency of Sebou [online]. Available at: http://www.abhsebou.ma/presentation-du-bassin/eaux-de-surface/. Accessed: 16 April 2020

ABHT (2007) Atlas des zones inondables. Hydraulic Basin Agency of Tensift document [online]. Available at: http://www.eau-tensift.net. Accessed: 18 April 2020

ABHT (2010) Plan Directeur d'Aménagement Intégré des Ressources en Eau des bassins du Tensift, Ksob et Igouzoulen,. Hydraulic Basin Agency of Tensift PDAIRE document

ABHT (2019) Rôle des Agences de Bassins dans la prévention et la gestion du risque naturel d'inondations. Hydraulic Basin Agency of Tensift communication, in Workshop for Training and Informing Focal Points in charge of Risks Management, Marrakech, Morocco [online]. Available at: https://www.gestionrisques.ma/. Accessed: 11 April 2020

Albergel J (2008) Place des petits barrages dans la mobilisation des eaux de surface et dans la lutte contre l'érosion au Maghreb et au Moyen-Orient. In: Roose É et al (ed) Efficacité de la gestion de l'eau et de la fertilité des sols en milieux semi-arides, pp 31-43. Paris, AUF, EAC, ENFI, IRD

Arthurton R, Le Tissier M, Snoussi M, Kitheka J, Shaghude Y, Kane A, Flöser G, Kremer H (2008) AfriCat: LOICZ — global change assessment and synthesis of river catchment — coastal sea interactions and human dimensions in Africa. LOICZ Reports \& Studies No. 30

AUA (2017) La carte d'aptitude à l'urbanisation de la province d'Al Hoceima. Al Hoceima Urban Agency communication. In: OECD workshop on risks prevention in Morocco, Fez, Morocco

AUT (2017) Documents d'urbanisme entre planification urbaine et gestion des risques -Etude géotechnique et carte d'aptitude à l'urbanisation de la ville de Taounate. Taza Urban Agency communication. In: OECD workshop on knowledge and risk assessment in Morocco, Rabat, Morocco

Azhari M, Loudyi D (2019) Downscaling climate projections and hydrologic responses for regional water resources assessment: case of the Oum Er Rbia river basin, Morocco. J Eng Res Appl 7:49-58

Bai L, Wang N, Jiao J, Chen Y, Tang B, Wang H, Chen Y, Yan X, Wang Z (2020) Soil erosion and sediment interception by check dams in a watershed for an extreme rainstorm on the Loess Plateau, China. Int J Sedim Res 35:408-416

Bennani O, Tramblay Y, Simon G, Frédéric L, Saidi ME (2019) Flood hazard mapping using two digital elevation models: application in a semi-arid environment of Morocco. Eur Sci J 15:338359

Boix-Fayos C, Vente DJ, Martínez-Mena M, Barbera GG, Castillo V (2008) The impact of land use change and check-dams on catchment sediment yield. Hydrol Process 22(25):4922-4935

Casa Aménagement (2020) Infrastructures: protection of the city of Casablanca from the floods of Oued Bouskoura [online]. Available at: https://www.casa-amenagement.ma/en/nos-projets/ super-collecteur-ouest. Accessed: 20 April 2020

Cour des Comptes (2016) Evaluation de la gestion des catastrophes naturelles. The Kingdom of Morocco court of auditors summary report [online]. Available at: http://www.courdescomptes. ma/. Accessed: 30 March 2020

Dahri N, Atoui A, Abida H (2014) Environmental impact assessment of a flood control channel in Sfax City, Tunisia. Int J Sci Eng 7(1):23-29

Daoudi L, Saidi MEM (2008) Floods in semi-arid zone: example of the Ourika (High Atlas of Marrakech, Morocco). Int Sci J Altern Energy 5(61):117-123

DesInventar Sendai (2014) Disaster information management system. United Nations office for disaster risk reduction, UNDRR [online]. Available at: https://www.desinventar.net/ DesInventar/. Accessed: 29 April 2020

DGE (2015) Plan National de l'Eau: Rapport Géneral. Moroccan General Directorate of Water report

DGE (2020) Data directly collected from the Moroccan General Directorate of Water

DGM (2017) Les données et les informations météorologiques/climatiques. National Meteorological Direction of Morocco communication. In: OECD workshop on knowledge and risk assessment in Morocco, Rabat, Morocco 
Diekkrüger B, Busche H, Klose A, Klose S, Rademacher C, Schulz O (2012) Impact of global change on hydrology and soil degradation - scenario analysis for the semi-arid Drâa catchment (South Morocco). In: Bogardi KJ et al (eds) River basins and change, pp pp 21-26. GWSP and UNESCO-IHE [online]. Available at: http://www.gwsp.org/fileadmin/documents_news/ GWSP_12_01_E-Lernbuch_Complete_RZ5.pdf. Accessed: 1 April 2020

Driouech F (2010) Distribution des précipitations hivernales sur le Maroc dans le cadre d'un changement climatique: descente d'échelle et incertitudes. $\mathrm{PhD}$ thesis, Institut National Polytechnique de Toulouse, France [online]. Available at: https://oatao.univ-toulouse.fr/7237/, Open Archive Toulouse Archive Ouverte. Accessed: 3 April 2020

Driouech F, Mahe G, Deque M, Dieulin C, El Heirech T, Milan M, Benabdelfadel A, Rouche N (2010) Evaluation d'impacts potentiels de changements climatiques sur l'hydrologie du bassin versant de la Moulouya au Maroc. In Proceedings of the sixth world FRIEND conference, vol 340, pp 561-567. IAHS Pub, Fez, Morocco

DRPE (2013) Etude d'actualisation du plan national de protection contre les inondations. CID/ISL report RM12-70 for the Moroccan Water Department

DRPE (2019) Rôle de la Direction de la Recherche et de la Planification de l'Eau dans la Gestion des Risques d'Inondations. Moroccan research and water planning directorate, DRPE communication. In: Workshop for training and informing focal points in charge of risks management, Marrakech, Morocco [online]. Available at: https://www.gestionrisques.ma/. Accessed: 10 April 2020

EM-DAT (2020) The OFDA/CRED international disaster database, Université Catholique de Louvain, Brussels, Belgium [online]. Available at: https://www.emdat.be/. Accessed: 20 April 2020

EMWIS (2005) Base de données SIG du plan national de protection contre les inondations et impacts des ouvrages de protection sur l'environnement. In: Seminar of information on SEMIDE: euro-mediterranean information system on know-how in the water sector, Rabat, Morocco [online]. Available at: http://www.emwis.org/. Accessed: 22 April 2020

HCP (2014) Moroccan population census, high commissioner for planning in Morocco report [online]. Available at: https://www.rgph2014.hcp.ma/Note-sur-les-premiers-resultats-duRecensement-General-de-la-Population-et-de-1-Habitat-2014_a369.html. Accessed: 11 May 2020

Hill T, Westbrook R (1997) SWOT analysis: it's time for a product recall. Long Range Plan 30 (1):46-52

IPCC (2007) Summary for policymakers. In: Solomon S et al (eds) Climate change 2007: the physical science basis. Contribution of working group I to the fourth assessment report of the intergovernmental panel on climate change. Cambridge University Press, Cambridge, United Kingdom and New York, NY, USA

Issara S, Merrouchi R, Nouni N (2010) Intensification and automation of Moroccan meteorological observation network for the improvement of weather forecasting and warning system. National meteorological direction of Morocco (DMN) poster presentation. In: TECO-2010 WMO technical conference on meteorological and environmental instruments and methods of observation, Helsinki, Finland

Jaouda I, Akhssas A, Ouadif L, Bahi L, Elkasri J, Souidi H, Soussi H (2020) Study of soil erosion risks using remote sensing in Ouergha River watershed (Morocco). In: Akhssas et al (eds) The 7th international congress on water, waste and environment, Salé, Morocco. E3S Web of conferences 150 [online]. Available at: https://www.e3s-conferences.org/. Accessed: 15 April 2020

JICA (2004) The master plan study on flood forecasting and warning system for Atlas region in the Kingdom of Morocco. Japan International Cooperation Agency final report, volume 2 main report [online]. Available at: https://openjicareport.jica.go.jp/pdf/11750825_01.PDF. Accessed: 2 May 2020

Jouve A (2006) Les trois temps de l'eau au Maroc: l'eau du ciel, l'eau d'Etat, l'eau privée. Confluences Méditerranée 58(3):51-61 
Lydec (2014) Schéma Directeur d'Assainissement. Aménagements de renforcement du réseau d'assainissement existant des zones urbanisées des communes de Casablanca et Mohammedia

Marchane A, Tramblay Y, Hanich L, Ruelland D, Jarlan L (2017) Climate change impacts on surface water resources in the Rheraya catchment (High Atlas, Morocco). Hydrol Sci J 62 (6):979-995

MI (2020) Ongoing projects, ministry of interior national portal for Morocco's integrated disaster risk management and resilience program. Available at: https://www.gestionrisques.ma/ Realisations/projets_en_cours.aspx. Accessed: 05 May 2020

Michel-Kerjan E, Scawthorn C, Baeumler AEN, Banerjee A, Rondot P, Medouar M, Mahul O, Boudreau L, Davila-Bonazzi A, Dana J (2014) Building Morocco's resilience: inputs for an integrated risk management strategy. World Bank report 83782 [online]. Available at: http:// documents.worldbank.org/curated/en/703601468060288949/Building-Moroccos-resilienceinputs-for-an-integrated-risk-management-strategy. Accessed: 7 April 2020

Midaoui A, Lahrach A, Chaouni A, Bourak A, Benaabidate L, Boukharas L (2015) Integration of GIS and HEC-RAS in floods modeling of the Ouergha river, northern Morocco. Eur Sci J ESJ 11:196-204

Moujahid M, Stour L, Agoumi A, Saidi A (2018) Regional approach for the analysis of annual maximum daily precipitation in northern Morocco. Weather Climate Extremes 21:43-51

OECD (2014) Recommendation of the council on the governance of critical risks. Meeting of the organisation for economic co-operation and development council at ministerial level, Paris, France [online]. Available at: http://www.oecd.org/gov/risk/Critical-Risks-Recommendation. pdf. Accessed: 8 May 2020

OECD (2016) OECD review of risk management policies Morocco. The organisation for economic co-operation and development, OECD Publishing, Paris [online]. Available at: https://www.oecd-ilibrary.org/governance/oecd-review-of-risk-management-policiesmorocco_9789264276482-en. Accessed 23 April 2020

OECD (2017a) Mieux évaluer les risques au Maroc: Quels besoins? Quels outils? Quelle gouvernance? The organisation for economic co-operation and development report presentation, in OECD workshop on knowledge and risk assessment in Morocco, Rabat, Morocco

OECD (2017b) OECD review of risk management policies Morocco. The organisation for economic co-operation and development, OECD Publishing, Paris [online]. Available at: https://www.oecd.org/gov/oecd-review-of-risk-management-policies-morocco9789264276482-en.htm. Accessed 21 April 2020

OECD (2018) Guide pratique: Connaitre et évaluer les risques de catastrophes naturelles au Maroc. The organisation for economic co-operation and development document at the national portal for Morocco integrated disaster risk management and resilience program. Available at: https://www.gestionrisques.ma/telecharger/guides.aspx. Accessed 15 April 2020

OECD (2019) Gestion des risques au Maroc: Progrès réalisés et enjeux pour l'avenir. The organisation for economic co-operation and development evaluation report at the national portal for Morocco integrated disaster risk management and resilience program. Available at https://www.gestionrisques.ma/web/files/Rapport_d_evaluation_OCDE.pdf. Accessed: 19 May 2020

ORMVAG (2017) Le Plan Agricole Régional de Rabat-Salé-Kénitra: Un modèle de gouvernance territoriale pour un développement durable. Regional Agricultural Development Office of El Gharb communication. In: 5th international seminar SESAME, agropolis international, Montpellier, France [online]. Available at: https://www.agropolis.fr/actualites/retourseminaire-international-sesame-5-2017.php. Accessed 3 May 2020

PNE (2015) Plan National de l'Eau, Moroccan Water Department document

PNI (2002) Étude du Plan National de Protection contre les Inondations et impacts des ouvrages de protection sur l'environnement. Moroccan State Secretary in charge of water, Summary report

PNI (2010) Étude d'actualisation du Plan National de Protection contre les Inondations. Moroccan General Directorate of Water report 
Saidi MEM, Daoudi L, Aresmouk M, Blali A (2003) Rôle du milieu physique dans l'amplification des crues en milieu montagnard: exemple de la crue du 17 août 1995 dans la vallée de l'Ourika (Haut-Atlas, Maroc). Sécheresse 14(2):1-8

Scawthorn C (2017) Modèle d'évaluation probabiliste multi-risques MnhPRA et la voie à suivre, communication. In: OECD workshop on knowledge and risk assessment in Morocco, Rabat, Morocco

Seif-Ennasr M, Zaaboul R, Hirich A, Caroletti GN, Bouchaou L, El Morjani Z, Beraaouz E, McDonnell RA, Choukr-Allah R (2016) Climate change and adaptive water management measures in Chtouka Aït Baha region (Morocco). Sci Total Environ 573:862-875

SEEE (Secrétariat d'État chargé de l'Eau et de l'Environnement), Environment Department (2008) Étude pour la réalisation d'une cartographie et d'un Systèmed'Information Géographique sur les risques majeurs au Maroc. Mission 1: Identification des risques - Le risque d'inondation

SEEE (Secrétariat d'Etat chargé de l'Eau et de l'Environnement). SEEE/UNDP/DEPP/ HYDRAUMET (2008) Rapport Étude V\&A s/ SCN, Mission III: Adaptation.Projet SCN-CC/00047842/2006. Étude vulnérabilité et adaptation du Maroc face aux changements climatiques. Rapport de synthèse - Mission 1 : Étude de lavulnérabilité

Sinan M, Belhouji A (2016) Impact of the climate change on the climate and the water resources of Morocco on horizons 2020, 2050 and 2080 and measures of adaptation. La Houille Blanche 4:32-39

Singla S (2009) Impact du changement climatique global sur les régimes hydroclimatiques au Maroc: tendances, ruptures et effets anthropiques sur les écoulements. Master Thesis, Université de Montpellier 2 [online]. Available at: https://www.documentation.ird.fr/hor/fdi: 010055323, All rights reserved. Accessed: 13 May 2020

SNE (2009) Stratégie Nationale de l'Eau. Moroccan state secretary in charge of water document [online]. Available at: http://www.environnement.gov.ma/PDFs/EAU/STRATEGIE_EAU.pdf. Accessed: 10 May 2020

Syvitski JPM (2008) Deltas at risk. Sustain Sci 3:23-32

UNEP (2008) Africa: Atlas of our changing environment. Division of early warning and assessment (DEWA), United Nations environment programme. Nairobi, Kenya [online]. Available at: http://www.unep.org/dewa/africa/africaAtlas/PDF/en/Chapter3b.pdf. Accessed: 7 April 2020

UNISDR (2015) Sendai framework for disaster risk reduction 2015-2030. United Nations office for disaster risk reduction publication UNISDR/GE/2015-ICLUX EN5000 1st edition, Geneva, Switzerland [online]. Available at: https://www.undrr.org/publication/sendaiframework-disaster-risk-reduction-2015-2030. Accessed: 05 May 2020

Varnes D (1984) Landslide hazard zonation: a review of principles and practice. Natural hazards 3, commission on landslides of the IAEG, UNESCO, Paris, France

Verner D (2012) Adaptation to a changing climate in the Arab countries: a case for adaptation governance and leadership in building climate resilience. MENA development report. World Bank, Washington, DC [online]. Available at: https://openknowledge.worldbank.org/handle/ 10986/12216. Accessed: 8 April 2020

WB (2011a) Adaptation au changement climatique et aux désastres naturels des villes côtières d'Afrique du Nord. Phase 1: Évaluation des risques en situation actuelle et à l'horizon 2030 pour la ville de Casablanca. World Bank report, Egis BCEOM International/IAU-IDF/BRGM, GED 80823T

WB (2011b) Adaptation au changement climatique et aux désastres naturels des villes côtières d'Afrique du Nord. Phase 1: Évaluation des risques en situation actuelle et à l'horizon 2030 pour la vallée du Bouregreg. World Bank report, Egis BCEOM International/IAU-IDF/BRGM, GED 80823T

WB (2011c) Climate change adaptation and natural disasters preparedness in the coastal cities of North Africa. World Bank report, Egis BCEOM International/IAU-IDF/BRGM, GED 80823T

WB (2012) What if scenario analysis report, Morocco natural hazards probabilistic risk analysis and national strategy development. The Ministry of General Affairs and Governance, prepared by RMSI Ltd 
WB (2013) Building Morocco's resilience: inputs for an integrated risk management strategy public. World Bank working paper. Available at: http://documents.worldbank.org/curated/en/ 2014/01/19226575/building-moroccos-resilience-inputs-integrated-risk-management-strategy. Accessed: 10 April 2020

WB (2016) Climate change knowledge portal. World Bank group [online]. Available at: https:// climateknowledgeportal.worldbank.org/country/morocco. Accessed: 15 April 2020

WB (2019) Morocco - disaster risk management development policy loan with a Catastrophe deferred drawdown option project. World Bank Group document, Washington, DC [online]. Available at: http://documents.worldbank.org/curated/en/500751580292321681/MoroccoDisaster-Risk-Management-Development-Policy-Loan-with-a-Catastrophe-DeferredDrawdown-Option-Project. Accessed: 6 May 2020

Yuan S, Li Z, Li P, Xu G, Gao H, Xiao L, Wang F, Wang T (2019) Influence of check dams on flood and erosion dynamic processes of a small watershed in the loss plateau. Water 11:834

Zemzami M, Benaabidate L, Layan B, Dridri A (2012) Design flood estimation in ungauged catchments and statistical characterization using principal components analysis: application of Gradex method in Upper Moulouya. Hydrol Process 27(2):186-195

Zkhiri W, Tramblay Y, Hanich L, Berjamy B (2017) Regional flood frequency analysis in the High Atlas mountainous catchments of Morocco. Nat Hazards 86:953-967

Open Access This chapter is licensed under the terms of the Creative Commons Attribution 4.0 International License (http://creativecommons.org/licenses/by/4.0/), which permits use, sharing, adaptation, distribution and reproduction in any medium or format, as long as you give appropriate credit to the original author(s) and the source, provide a link to the Creative Commons license and indicate if changes were made.

The images or other third party material in this chapter are included in the chapter's Creative Commons license, unless indicated otherwise in a credit line to the material. If material is not included in the chapter's Creative Commons license and your intended use is not permitted by statutory regulation or exceeds the permitted use, you will need to obtain permission directly from the copyright holder.

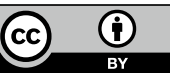

